\title{
Mapping Maize Water Stress Based on UAV Multispectral Remote Sensing
}

\author{
Liyuan Zhang ${ }^{1,2}$, Huihui Zhang ${ }^{3}\left(\mathbb{D}\right.$, Yaxiao Niu ${ }^{1,2}$ and Wenting Han ${ }^{1,4, *}$ \\ 1 College of Mechanical and Electronic Engineering, Northwest A\&F University, Yangling 712100, Shaanxi, \\ China; liyuanzhang@nwafu.edu.cn (L.Z.); niuyaxiao@nwafu.edu.cn (Y.N.) \\ 2 Key Laboratory of Agricultural Internet of Things, Ministry of Agriculture, Yangling 712100, Shaanxi, China \\ 3 Water Management and Systems Research Unit, USDA-ARS, 2150 Centre Avenue, Bldg. D., \\ Fort Collins, CO 80526, USA; huihui.zhang@ars.usda.gov \\ 4 Institute of Soil and Water Conservation, Northwest A\&F University, Yangling 712100, Shaanxi, China \\ * Correspondence: hanwt2000@126.com; Tel.: +86-029-8709-1325
}

Received: 30 January 2019; Accepted: 9 March 2019; Published: 13 March 2019

check for updates

\begin{abstract}
Mapping maize water stress status and monitoring its spatial variability at a farm scale are a prerequisite for precision irrigation. High-resolution multispectral images acquired from an unmanned aerial vehicle (UAV) were used to evaluate the applicability of the data in mapping water stress status of maize under different levels of deficit irrigation at the late vegetative, reproductive and maturation growth stages. Canopy temperature, field air temperature and relative humidity obtained by a handheld infrared thermometer and a portable air temperature/relative humidity meter were used to establish a crop water stress index (CWSI) empirical model under the weather conditions in Ordos, Inner Mongolia, China. Nine vegetation indices (VIs) related to crop water stress were derived from the UAV multispectral imagery and used to establish CWSI inversion models. The results showed that non-water-stressed baseline had significant difference in the reproductive and maturation stages with an increase of $2.1^{\circ} \mathrm{C}$, however, the non-transpiring baseline did not change significantly with an increase of $0.1^{\circ} \mathrm{C}$. The ratio of transformed chlorophyll absorption in reflectance index (TCARI) and renormalized difference vegetation index (RDVI), and the TCARI and soil-adjusted vegetation index (SAVI) had the best correlations with CWSI. $\mathrm{R}^{2}$ values were 0.47 and 0.50 for TCARI/RDVI and TCARI/SAVI at the reproductive and maturation stages, respectively; and 0.81 and 0.80 for TCARI/RDVI and TCARI/SAVI at the late reproductive and maturation stages, respectively. Compared to CWSI calculated by on-site measurements, CWSI values retrieved by VI-CWSI regression models established in this study had more abilities to assess the field variability of crop and soil. This study demonstrates the potentiality of using high-resolution UAV multispectral imagery to map maize water stress.
\end{abstract}

Keywords: crop water stress index (CWSI); vegetation index; regression model; non-water-stressed baseline; non-transpiring baseline

\section{Introduction}

Water resource scarcity is one of the most important challenges for agricultural water management, especially in arid and semi-arid areas all over the world. Due to drought associated with climate change, agricultural water resources will be reduced, it is necessary to achieve maximum production per unit of applied irrigation water. As one of the important ways to enhance water-use efficiency, regulated deficit irrigation may solve this dilemma [1-4]. However, to achieve a delicate balance between yield and irrigation water, effective monitoring methods for crop water stress are necessary [5-7]. 
Currently, crop water stress can be detected based on soil moisture content, crop physiological characteristics (e.g., stomatal conductance, leaf water potential) and remote-sensing technology [8]. On-site measurements of soil water content and crop physiological characteristics are time-consuming, laborious and costly, and do not take into account the spatial variability of soil and crops $[9,10]$. Measurements of canopy temperature or canopy reflectance based on remote-sensing technology have the advantages of being easy, non-destructive and of low labor intensity $[8,11]$.

Since numerous data from various remote sensing imagery platforms have become available, studies of monitoring crop water stress have been done by satellite [12-14] and aerial [15-18] remote-sensing technology. However, crop monitoring applications are highly demanding with respect to temporal frequency (1-3 days revisit) of key image acquisition, and spatial resolution requirements are driven by the minimum management unit that can be in the range of 1-10 $\mathrm{m}$ [19]. Satellite remote sensing has the disadvantages of low spatial-temporal resolution and vulnerability to weather. For instance, Landsat and SPOT has spatial resolution of 30 and $20 \mathrm{~m}$, and revisit time 16 and 26 days, respectively. It is often difficult to meet the monitoring need of crop water stress at a farm scale. Aerial remote sensing has the disadvantages of high operational difficulty and high operating cost. Due to the advantages of low cost, easy to construct, convenient transportation, high flexibility, short operating cycle and high spatial-temporal resolution, an unmanned aerial vehicle (UAV) remote-sensing system could collect crop information in a desirable spatial-temporal resolution [20-22]. This makes it more suitable to monitor crop water stress quickly and meticulously at a farm scale.

Due to the principle that crop canopy temperature (Tc) rises with increasing water stress in comparison to crop under well irrigation condition [23], several researchers integrated thermal cameras into UAV platforms to evaluate crop water stress of the entire field. Zhang et al. [24] used canopy temperature characteristics derived from UAV thermal images to monitor cotton water status. The results suggested canopy temperature standard deviation (CTSD) was sensitive to crop water stress with a coefficient of determination $\left(\mathrm{R}^{2}\right)$ of 0.88 between CTSD and stomatal conductance. Martínez et al. [25] assessed the potential of UAV thermal imaging for monitoring plant water stress in a commercial sugar beet field. The results indicated that a lightweight UAV canopy temperature system including an infrared thermometer and a microcontroller board as data logger, was robust and reliable, but there were some constraints related to weather conditions and delimitation of the area covered by the infrared sensor.

However, Tc is not only affected by water supply but also by the actual micro-meteorological conditions (such as, air temperature (Ta), relative humidity (RH) and vapor pressure deficit (VPD)). Therefore, aiming to reduce the influence of meteorological conditions, several temperature-based indices were developed over the last few decades [17]. The crop water stress index (CWSI) based on canopy temperature and some meteorological parameters has been investigated as an effective method to monitor the water status of various plants by many previous researchers, such as maize [26-29], cotton [30,31], grapevine [16,32-34], peaches [35-37] and olives [38-40]. Good relationships between CWSI and other on-site crop water stress indicators have been shown, such as soil water content [41-44], leaf water potential $[16,45,46]$ and stomatal conductance $[32,33,47]$. There are two widely used CWSI models: the empirical model proposed by Idso et al. [48] and the theoretical model proposed by Jackson et al. [49]. Compared to the theoretical model, the empirical model is easier to establish and only needs Tc, Ta and RH.

When establishing the CWSI empirical model, there are two common methods to establish non-water-stressed baseline (NWSB) and non-transpiring (stomata fully closed) baseline (NTB), namely using wet and dry reference, and using the linear segment in the plot of $d T_{L L}$ (the lower limit of canopy-air temperature difference) vs. VPD (vapor pressure deficit). For example, Wang et al. [44] established the CWSI empirical model for winter wheat planted in Luancheng area, Hebei Province, China, by using wet and dry reference to establish NWSB and NTB. However, to ensure the monitoring effect of crop water stress, it is necessary to select the wet and dry reference position in practical applications carefully. Taghvaeian et al. [42] established the CWSI empirical model for maize planted 
in Northeastern Colorado, USA by using the linear segment in the plot of $d T_{L L}$ vs. VPD. Compared to using wet and dry reference, it is easier to establish NWSB and NTB by using the linear segment in the plot of $d T_{L L}$ vs. VPD in practical applications.

As the key parameter to estimate CWSI, Tc conventionally relies on manual or continuous point measurements $[4,31,50]$. However, the ground-based handheld thermometer approach is labor-intensive, costly, and impractical when monitoring large areas; furthermore, water stress status at the agricultural fields commonly has spatial variability due to spatially heterogeneous biophysical conditions between plants or even within a plant [51-54]. To monitor crop water stress and its spatial variability at a field scale, several researchers started to obtain CWSI maps based on a UAV remote-sensing system. Bellvert et al. [55] characterized the spatial variability in water status across vineyards by CWSI maps. The results showed that the CWSI maps thus obtained by UAV thermal imagery were effective in assessing the spatial variability of water stress across the vineyard. Zhang et al. [30] evaluated cotton water stress and its spatial variability by UAV thermal remote-sensing system. The results showed that the $\mathrm{R}^{2}$ between CWSI and leaf stomatal conductance of cotton planted in Yangling, Shaanxi, China was 0.84 .

However, due to the load capacity limitation of UAV platforms, the thermal infrared sensors currently mounted are mostly lightweight uncooled thermal infrared cameras that have the problems of unstable canopy temperature acquisition, low mosaic precision (e.g., number of tie-points, number of geolocated images and mean re-projection error etc.) and needing complex pretreatments (e.g., radiometric calibration, temperature correction and canopy temperature extraction) $[17,56]$. Compared to the thermal infrared system, a UAV-based multispectral remote-sensing system has the advantages of stable information acquisition and mature mosaic technology. It could be a supplement to ground-based infrared thermometry to obtain CWSI maps with a high spatial-temporal resolution at the field scale.

A vegetation index $(\mathrm{VI})$, which is the mathematical operation result of reflectivity of vegetation and other ground objects in the corresponding band [57], can be used to monitor surface vegetation condition. VI has been successfully applied to land cover classification, environmental change, and drought monitoring [33]. Water stress could affect crop canopy structure, photosynthesis and leaf moisture content. VIs used to monitor crop water stress can be divided into four categories: structure index, chlorophyll index, lutein index and moisture index [8]. The structure and chlorophyll indices based on visible, near infrared and red-edge bands are more widely used, such as normalized difference vegetation index (NDVI) [58], renormalized difference vegetation index (RDVI) [33], soil-adjusted vegetation index (SAVI) [59], optimization of soil-adjusted vegetation index (OSAVI) [60], transformed chlorophyll absorption in reflectance index (TCARI) [60]. To reduce the sensitivity of TCARI to canopy structure changes, TCARI/OSAVI was used by Haboudane et al. [60]. When structure index was used to describe canopy structure, its effect would be affected by the soil, crops, and planting structure. To reduce the sensitivity of TCARI to canopy structure changes, in this study NDVI, RDVI, SAVI and OSAVI were used, respectively.

To map maize water status and monitor its spatial variability at a farm scale, in this study, the CWSI empirical model was developed by the ground-based data and high-resolution UAV-based multispectral images of maize under various levels of deficit irrigation at different growth stages. The linear segment in the plot of $d T_{L L}$ vs. VPD was used to establish the NWSB and NTB. VIs related to water stress derived from multispectral imagery were used to establish CWSI inversion model. Since, the local conditions, irrigation technique, and management practices can greatly influence the applicability of remote sensing systems for water status evaluation. The specific objectives of this study were:

(1) To develop the NWSB and NTB for maize under the weather condition in Ordos, Inner Mongolia, China;

(2) To evaluate UAV-based multispectral VIs that are sensitive to maize water stress and establish CWSI regression models; 
(3) To obtain CWSI maps with high spatial-temporal resolution at the field scale using the CWSI regression models.

\section{Materials and Methods}

\subsection{Study Site}

This study was conducted in a 1.13 ha research field $\left(40^{\circ} 26^{\prime} 0.29^{\prime \prime} \mathrm{N}, 109^{\circ} 36^{\prime} 25.99^{\prime \prime} \mathrm{E}\right.$, Elev. $\left.1010 \mathrm{~m}\right)$, located in Zhaojun Town, Dalate Banner, Ordos, Inner Mongolia, China. Soil samples at the depths of 30, 60 and $90 \mathrm{~cm}$ were collected from the sampling plot (yellow circle in Figure 1a) to estimate the field hold capacity (volumetric) which were $13.6 \%, 13.2 \%$ and $12.3 \%$, respectively. The average permanent wilting point of the soil profile was assumed to be $5.6 \%$ (volumetric) according to Lv et al. [61]. The soil bulk density was 1.56 . The mixture of soil samples at the depths of 30, 60 and $90 \mathrm{~cm}$ were used to estimate other soil characteristics. The soil type was a loamy sand $(80.7 \%$ sand, $13.7 \%$ powder, and 5.6\% clay), using the United States Department of Agriculture soil taxonomy. The soil pH, organic matter and C content were 9.27, $47.17 \mathrm{~g} / \mathrm{Kg}$ and $27.35 \mathrm{~g} / \mathrm{Kg}$, respectively. Maize (Junkai 918) was planted on 20 May 2017, with $0.58 \mathrm{~m}$ row spacing and $0.25 \mathrm{~m}$ plant spacing and the row direction was East-West. The maize emerged on June 1, headed on July 20, was harvested on September 7 (silage) with a 110-day lifespan.

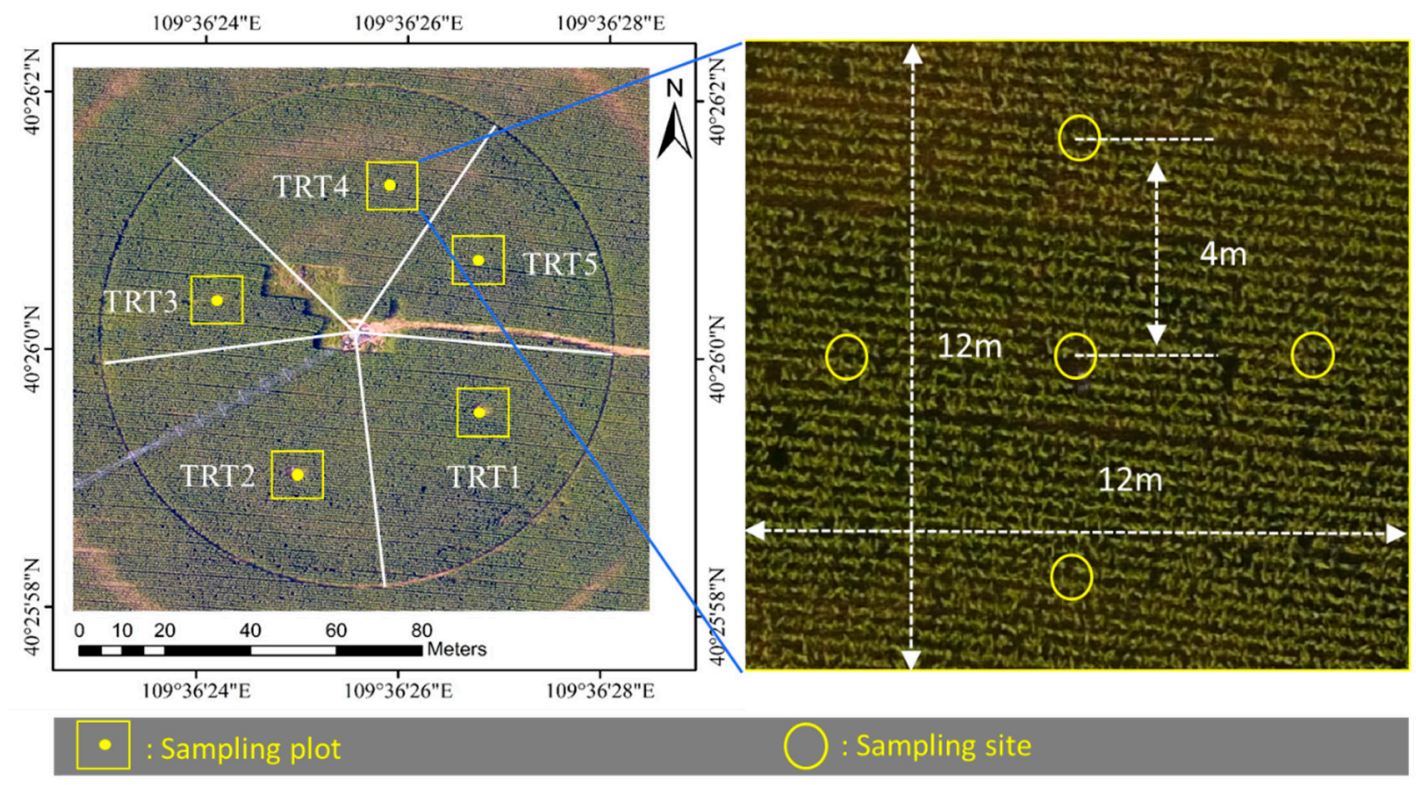

(a)

(b)

Figure 1. Aerial view of the experimental field indicating treatment region division (a), the location of sampling plots (a) and sampling sites (b). Air temperature and humidity, and canopy temperature were taken at each sampling site.

\subsection{Experimental Design}

The study field was divided into five treatment (TRT) regions (Figure 1a) with different levels of deficit irrigation at the crop late vegetative, reproductive and maturation growth stages. A $12 \times 12 \mathrm{~m}^{2}$ area within each TRT region was chosen as a sampling plot for the TRT (Figure 1a) and data collection from five sampling sites within the sampling plot were indicated in Figure 1b. The non-stressed crop evapotranspiration (ET) was estimated by reference evapotranspiration and single crop coefficient approach [62]. The crop coefficient was equal to $0.55,1.09$ and 0.45 in the initial, mid-season and late-season development stages. The total crop water requirement of the full watered maize during the late vegetation, reproductive and maturation stages was $407 \mathrm{~mm}$ which was close to the total 
applied water $(402 \mathrm{~mm})$ of the control treatment region (TRT 1). Therefore, different levels of deficit irrigation were described by the percentages of applied water depth of TRT 1 during the late vegetation, reproductive and maturation stages. For example, during the late vegetation stage, $84 \%$ of the applied water depth at TRT 1 was applied to TRT 2 (Table 1)

Table 1. Experimental treatments and total applied water depth (percentage of full irrigation treatment in parentheses) that includes amount of irrigation and precipitation in the late vegetative, reproductive and maturation stages in 2017.

\begin{tabular}{ccccc}
\hline & \multicolumn{3}{c}{ Applied Water Depth/mm } \\
\cline { 2 - 5 } Treatment & $\begin{array}{c}\text { Late Vegetative } \\
(\mathbf{0 7 . 0 4 - 0 7 . 2 8 )}\end{array}$ & $\begin{array}{c}\text { Reproductive } \\
\mathbf{( 0 7 . 2 9 - 0 8 . 2 0 )}\end{array}$ & $\begin{array}{c}\text { Maturation } \\
\mathbf{( 0 8 . 2 1 - 0 9 . 0 7 )}\end{array}$ & Total \\
\hline TRT 1 & $188(100 \%)$ & $132(100 \%)$ & $82(100 \%)$ & 402 \\
TRT 2 & $158(84 \%)$ & $128(97 \%)$ & $43(52 \%)$ & 329 \\
TRT 3 & $158(84 \%)$ & $125(95 \%)$ & $43(52 \%)$ & 326 \\
TRT 4 & $158(84 \%)$ & $91(69 \%)$ & $23(28 \%)$ & 272 \\
TRT 5 & $158(84 \%)$ & $124(94 \%)$ & $82(100 \%)$ & 365 \\
\hline
\end{tabular}

Irrigation was applied during the growing season by using a center pivot sprinkler system (Valmont Industries, Inc., Omaha, NE, USA) that has two spans and one end gun with a total length of $143.7 \mathrm{~m}$. More detailed information about the center pivot sprinkler system can be found in Li et al. [63]. The uniformity test of water application of the center pivot irrigation system was conducted in accordance with the standard ANSI/ASAE S436.1 and ISO 11545. The coefficient of uniformity of the first span (research field) calculated by the modified formula of Heermann and Hein [64] was 82.7\% under a walking speed of $20 \%$ of the full speed and $88.3 \%$ under a walking speed of $40 \%$ of the full speed using R3000 sprinklers. The amount of water applied to each treatment was measured and recorded by MIK-2000H flow meters (Meacon Automation Technology Co., Ltd, Hangzhou, China). The actual amount of irrigation and rainfall at each grown stage were shown in Table 1. In order to eliminate the interference of nutritional stress and weeds, fertilizer and herbicide were applied according to the planting experience.

\subsection{Measurement of Maize Canopy Temperature}

Maize canopy temperature (Tc) and UAV multispectral data were synchronously collected under clear sky conditions between 11:00-13:00 local time (Chinese standard time, 11:44-13:44) during the study period (2017.08.06 29, including the reproductive and maturation stages). Tc was measured by a handheld infrared thermometer (RAYTEK, ST60+, Raytek Inc, Santa Cruz, CA, USA). The temperature range and spectral range were $-32-600{ }^{\circ} \mathrm{C}$ and $8-14 \mu \mathrm{m}$, respectively. The measurement error was $\pm 1 \%$ of reading or $\pm 1{ }^{\circ} \mathrm{C}$, the lager value was adopted in the practical application. The emissivity value was set to 0.97 . To avoid the interference of the soil, the handheld infrared thermometer was used to sweep the canopy (about $120^{\circ}$ ) perpendicular to the row with $30 \mathrm{~cm}$ above the canopy and $15^{\circ}$ horizontal angle (Figure 2 ). At each sampling site three measurements of Tc were taken and the average value of these three readings was used to represent the sampling site. The average value of Tc measured at the five sampling sites (yellow circle in Figure 1b) was used to represent the status of the sampling plot. During each data collection day, a total of 15 canopy temperature measurements were obtained for each sampling plot. During the reproductive and maturation stages, the average plant heights were $263,258,252,253$ and $261 \mathrm{~cm}$ for TRTs $1 \sim 5$, respectively. 


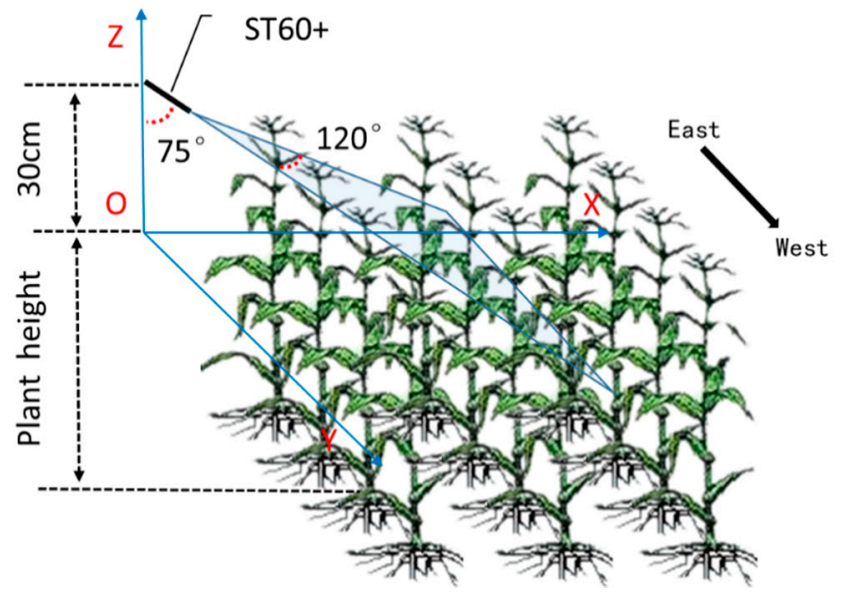

Figure 2. Schematic indicating measurement method of canopy temperature in each sampling site.

\subsection{Meteorological Data}

The field air temperature and relative humidity ( $\mathrm{Ta}_{-} \mathrm{f}$ and $\mathrm{RH} \_\mathrm{f}$ ) of each sample plots was obtained by a handheld hygrometer (Klimalogg Pro, TFA, Germany). During the study period Ta_f and RH_f were measured synchronously with Tc at a height of $2.2 \mathrm{~m}$ above the ground. The average of Ta_f and $\mathrm{RH} \_\mathrm{f}$ collected at the five sampling sites (Figure 1b) represented the status of one sampling plot. The weather data were measured at an automated weather station adjacent to the research field, which included rainfall, Ta and RH, net solar radiation, and wind speed ( $2 \mathrm{~m}$ above the reference grass surface). In addition to rainfall, the data acquisition interval was $30 \mathrm{~min}$. The main mean meteorological data during the study period including reproductive stage (07.29-08.20) and maturation stage (08.21-29) were shown in Table 2. The changing curves of meteorological data were shown in Figure A1.

Table 2. The main mean meteorological data during the study period including the reproductive stage and maturation stages in 2017.

\begin{tabular}{ccc}
\hline Parameter & $\begin{array}{c}\text { Reproductive } \\
\mathbf{( 0 7 . 2 9 - 0 8 . 2 0 )}\end{array}$ & $\begin{array}{c}\text { Maturation } \\
\mathbf{( 0 8 . 2 1 - 2 9 )}\end{array}$ \\
\hline Mean air temp. $/{ }^{\circ} \mathrm{C}$ & 22.11 & 17.21 \\
Max. air temp. $/{ }^{\circ} \mathrm{C}$ & 31.31 & 25.46 \\
Min. air temp. $/{ }^{\circ} \mathrm{C}$ & 13.61 & 9.24 \\
Min. relative humidity $/ \%$ & 29.78 & 33.23 \\
Mean net solar & 10.98 & 3.00 \\
radiation $/ \mathrm{MJ} \cdot \mathrm{m}^{-2} \cdot \mathrm{day}^{-1}$ & 0.47 & 0.28 \\
Mean wind speed $/ \mathrm{m} \cdot \mathrm{s}^{-1}$ & \\
\hline
\end{tabular}

\subsection{Soil Water Content Data}

Soil water content (SWC) was measured two or three times each week on the days before or after irrigation in each sampling plot by the traditional gravimetric method. At each sampling plot, three sampling locations were randomly chosen around the center. At each sampling site, soil samples at the depths of 30, 60 and $90 \mathrm{~cm}$ were collected by using soil augers. Soil samples were put in aluminum boxes to avoid the influence of evaporation. An electronic balance (DJ-2000A, Suzhou Jiangdong Precision Instrument CO., Ltd., Suzhou, China) with a measurement accuracy of $0.01 \mathrm{~g}$ was used to measure the weight of the aluminum boxes with and without soil samples. After weighting, 
uncapped aluminum boxes were dried to a constant weight by putting in an oven under $105^{\circ} \mathrm{C}$. SWC (volumetric) could be calculated by using Equation (1):

$$
S W C=\frac{W_{1}-W_{2}}{W_{2}-W_{3}} \times 1.56
$$

where $W_{1}$ presents the weight of aluminum box and soil sample before drying; $W_{2}$ presents the weight of aluminum box and soil sample after drying; $W_{3}$ presents the weight of aluminum box without soil sample; 1.56 is the specific soil bulk density of this study site. The changing curve of the average SWC (volumetric) at the depths of 30, 60 and $90 \mathrm{~cm}$ during the reproductive and maturation stages is shown in Figure 3.

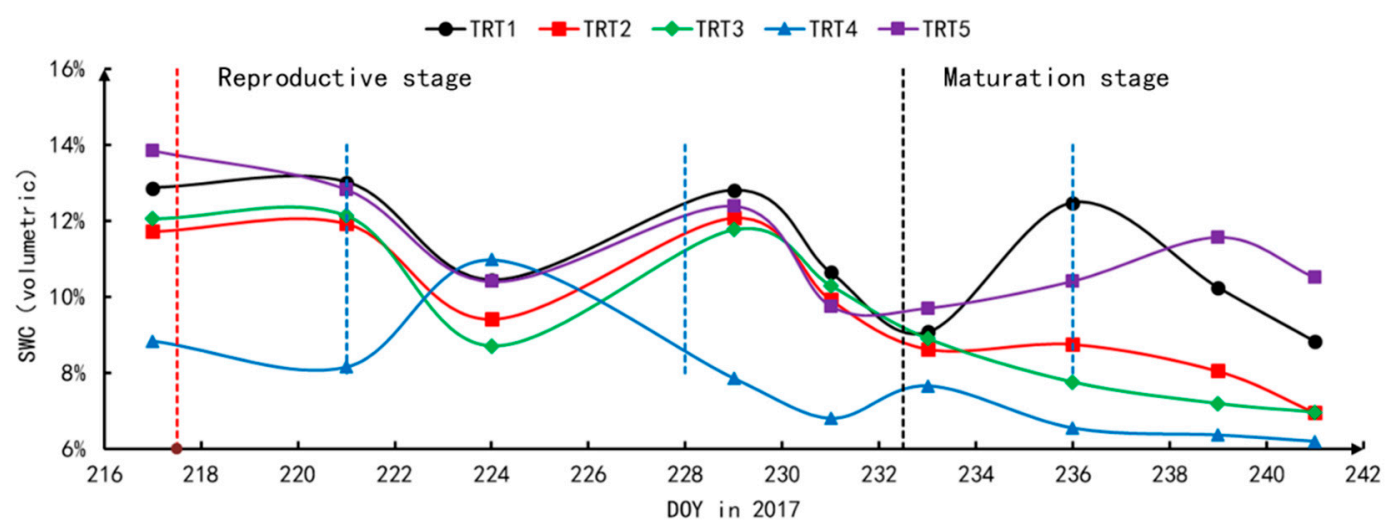

Figure 3. The changing curve of the average soil water content (SWC, volumetric) at the depths of 30, 60 and $90 \mathrm{~cm}$ during the reproductive and maturation stages in 2017. The black, red, green, blue and purple solid lines represent treatment regions (TRTs) $1 \sim 5$, respectively. The red dotted line is boundary between the late vegetation and reproductive stages. The black dotted line is boundary between the reproductive and maturation stages. The blue dotted lines indicate dates when data was taken for the calculation of non-water-stressed and non-transpiring baselines of the crop water stress index (CWSI).

\subsection{Unmanned Aerial Vehicle (UAV) Multispectral System and Data Collection}

Three types of UAV remote-sensing systems are generally used to collect agricultural information, namely fixed-wing, single-rotor and multi-rotors UAVs [65]. When selecting a kind of UAV platform, factors such as takeoff requirements, coverage area, load capacity, wind resistance, and cost and maintenance cost are needed to be considered [56]. In this study, a hexacopter UAV multispectral remote-sensing system (Figure 4) was developed with a Pixhawk autopilot (CUAV, Guangzhou, China), a RedEdge multispectral camera (MicaSense, Inc., WA, USA) and a MOY brushless gimbal (Moyouzhijia, Huizhou, China). This system had the advantages of easy to takeoff and land, low operation cost and maintenance cost. The core of the UAV system was a Flight Control board, Pixhawk, based on one 32 bit STM32F427 Cortex M4 core with float point unit and one 32 bit STM32F103 failsafe co-processor, which communicated with the six brushless controllers by six two-wire bi-directional wires (pulse width modulation). Pixhawk integrated two gyroscopes, two accelerometers, one magnetometer, and one barometer. The gimbal maintained the multispectral camera under a relatively stable state during the flight to obtain good quality multispectral images. The flight planning was conducted with ground control station software, Mission Planner, which allowed the user to generate a route of waypoints as a function of the sensor field of view (FOV), the degree of overlap between images and the ground resolution needed. Mission Planner could also display real-time flight data. Its main technical parameters were shown in Table 3. 


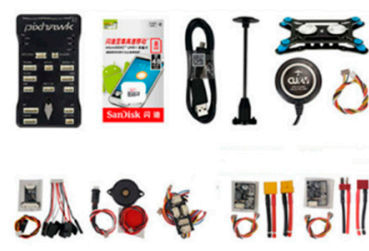

b) Pixhawk suite
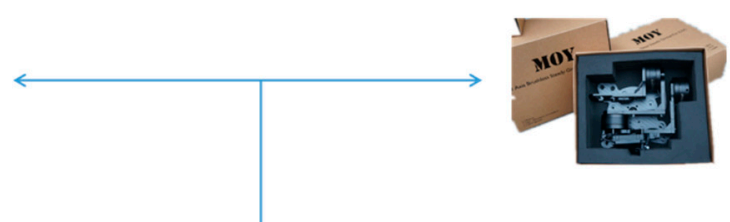

c) Gimbal and RedEedge

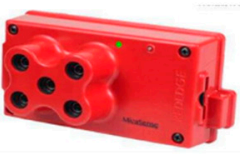

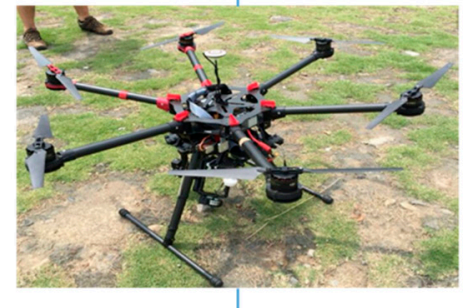

a) UAV platform
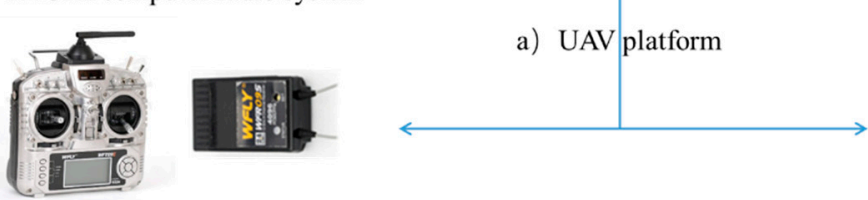

e) Ground control station

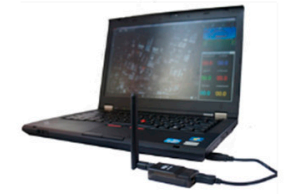

Figure 4. Schematic indicating the main components of UAV multispectral remote sensing system developed in this study.

Table 3. Main parameters of UAV multispectral image acquisition system.

\begin{tabular}{lll}
\hline & Parameter & \multicolumn{1}{c}{ Value } \\
\hline \multirow{4}{*}{ UAV } & Wheelbase & $900 \mathrm{~mm}$ \\
& Takeoff weight & $6 \mathrm{~kg}$ \\
& Payload & $2 \mathrm{~kg}$ \\
& Flight time & $18 \mathrm{~min}$ \\
& Communication radius & $3 \mathrm{~km}$ \\
& Speed & $5 \mathrm{~m} / \mathrm{s}$ \\
& Camera & MicaSense RedEdge \\
& Imager resolution & $1280 \times 960$ pixels \\
RedEdge & $4.8 \mathrm{~mm} \times 3.6 \mathrm{~mm}$ \\
\cline { 2 - 3 } & Imager size & Blue $(475 \mathrm{~nm})$, Green $(560 \mathrm{~nm})$, Red $(668 \mathrm{~nm})$, \\
& Spectral bands & Near infrared (IR) $(840 \mathrm{~nm})$, Red-edge $(717 \mathrm{~nm})$ \\
& Lens focal length & $5.5 \mathrm{~mm}$ fixed lens \\
& Lens field of view & $47.2^{\circ}$ horizontal field of view (HFOV) \\
& Weight & $150 \mathrm{~g}$ \\
& Dimension & $121 \mathrm{~mm} \times 66 \mathrm{~mm} \times 46 \mathrm{~mm}$ \\
\hline
\end{tabular}

During the study period (2017.06.20 08.29), eleven UAV flights were conducted on sunny day between 11:00-13:00 local time (Chinese standard time, 11:44-13:44) with the RedEdge camera lens vertically downwards, and $80 \%$ heading and side overlap. The flight height, speed and ground sample distance were $70 \mathrm{~m}$ (relative flying height), $5 \mathrm{~m} / \mathrm{s}$ and $4.7 \mathrm{~cm}$, respectively; 2185 images (5 bands) were collected during a single flight and Pix4DMapper software was used for image mosaicking. The multispectral images of diffuse reflector (reflectivity $58 \%$, size $3 \times 3 \mathrm{~m}$, Group VIII, USA) collected simultaneously at the same height were used to perform radiometric correction. Then, spectral reflectance of the objects was obtained. 


\subsection{Vegetation Indices' Selection and Calculation}

To establish a regression mode between UAV-based multispectral VI and CWSI, nine VIs, NDVI, RDVI, SAVI, OSAVI, TCARI, TCARI/NDVI, TCARI/RDVI, TCARI/SAVI, and TCARI/OSAVI were selected. Their calculation formulas are as follows:

$$
\begin{gathered}
\text { NDVI }=\frac{\rho_{\text {nir }}-\rho_{\text {red }}}{\rho_{\text {nir }}+\rho_{\text {red }}} \\
R D V I=\frac{\rho_{\text {nir }}-\rho_{\text {red }}}{\sqrt{\rho_{\text {nir }}+\rho_{\text {red }}}} \\
\text { SAVI }=\frac{(1+0.5) *\left(\rho_{\text {nir }}-\rho_{\text {red }}\right)}{\rho_{\text {nir }}-\rho_{\text {red }}+0.5} \\
\text { OSAVI }=\frac{(1+0.16) *\left(\rho_{\text {nir }}-\rho_{\text {red }}\right)}{\rho_{\text {nir }}-\rho_{\text {red }}+0.16} \\
\text { TCARI }=3\left[\left(\rho_{\text {rededge }}-\rho_{\text {red }}\right)-0.2\left(\rho_{\text {rededge }}-\rho_{\text {green }}\right) *\left(\rho_{\text {rededge }} / \rho_{\text {red }}\right)\right]
\end{gathered}
$$

where $\rho_{\text {nir }}, \rho_{\text {red }}, \rho_{\text {rededge }}$ and $\rho_{\text {green }}$ are reflectance values of ground objects in near-infrared, red, red-edge and green bands. A linear regression analysis between CWSI and VI was conducted to obtain the VI vs. CWSI regression model based on CWSI and VI of sampling plots. For statistical analysis, R programming language (R-3.4.3, https://www.r-project.org/) and the $\operatorname{lm}()$ function were used. The coefficient of determination $\left(R^{2}\right)$ and root mean square error (RMSE) were used as evaluating indicators.

\subsection{Crop Water Stress Index (CWSI) Calculation}

The empirical CWSI could be calculated by using Equations (7)-(10):

$$
C W S I=\frac{d T_{m}-d T_{L L}}{d T_{U L}-d T_{L L}}
$$

where $d T_{m}, d T_{L L}, d T_{U L}$ are actual measurement, lower limit and upper limit of canopy-temperature difference, respectively. The upper and lower limit canopy-air temperature difference are the so-called non-water-stressed baseline (NWSB) and non-transpiring baseline (NTB). They could be calculated by Equations (8) and (9) [22,37]:

$$
\begin{aligned}
& d T_{L L}=m \times V P D+b \\
& d T_{U L}=m \times V P G+b
\end{aligned}
$$

where $m, b$ are slope and intercept, respectively; VPD (vapor pressure deficit) is related to Ta and RH, and calculated by the following Equation (10) with the description of Walter et al. [66]:

$$
V P D=0.6108 \times \exp \left(\frac{17.27 T_{a}}{T_{a}+237.3}\right) \times\left(\frac{100-R H}{100}\right)
$$

where Ta is air temperature, $\mathrm{RH}$ is relative humidity. Vapor pressure gradient (VPG) is the change of VPD when the Ta increase by $b$, and calculated by the following Equation (11):

$$
V P G=0.6108 \times \exp \left(\frac{17.27\left(T_{a}+b\right)}{\left(T_{a}+b\right)+237.3}\right) \times\left(\frac{100-R H}{100}\right)-V P D
$$

where $b$ is the intercept in Equations (8) and (9). When CWSI is 0, it indicates no water stress, while CWSI is 1 , it indicates most severe stress.

After effective irrigation/rainfall, it is assumed that the soil water deficit is fully replenished and crop could obtain sufficient water. Thus, non-water-stressed condition exist and Tc-Ta values could be 
regarded as the values of the lower limit of canopy-air temperature difference [29,42]. Graph of hourly $d T_{L L}$ vs. VPD has a linear segment that extended for $2 \mathrm{~h}$ before and $2 \mathrm{~h}$ after the solar noon. This linear segment could be extracted to obtain the coefficients of Equations (8) and (9) by using simple linear regression $[42,67]$. In this study, after effective irrigation/rainfall, clear sky sunny days were chosen to continuously collect (local time 10:00 14:00, with an interval of $15 \mathrm{~min}$ ) Tc, Ta_f and RH_f in the full irrigation region (TRT1) during the reproductive and maturation stages. During the reproductive stage, 9 August and 16 August 2017 (clear sky sunny day, day of year (DOY) 221 and 228) were chosen and 28 groups of samples (Tc, Ta_f and RH_f) were obtained. During the maturation stage, 24 August 2017 (clear sky sunny day, DOY 236) was chosen and 13 groups of samples were obtained. When drawing the $d T_{L L} \sim$ VPD scatterplot, three-step moving average was used to reduce volatility according to Idso (1981) [48], making the fitting curve could represent the lower limit of Tc-Ta better under different saturated VPD.

\section{Results}

\subsection{Non-Water-Stressed Baselines (NWSBs) and Non-Transpiring Baselines (NTBs) of CWSI}

It was observed that the slope and intercept of NWSB changed in the maturation stage. A similar observation was made by previous researchers among crops, such as sunflower [43,68], wheat [69], barley [69] and maize [70]. Hence, different NWSBs were developed in this study for the reproductive and maturation stages. The $d T_{L L}$ vs. VPD scatterplots were shown in Figures $5 \mathrm{a}$ and $5 \mathrm{~b}$, respectively. The corresponding NWSBs were shown as Equations (12) and (13). The average NWSBs of the reproductive and maturation stages were $-11.0^{\circ} \mathrm{C}$ and $-8.9^{\circ} \mathrm{C}$, rose by $2.1^{\circ} \mathrm{C}$. In calculating CWSI, the NTB is estimated using the same coefficients developed for NWSB, and using VPG instead of VPD. The change in NWSB coefficients from the reproductive to maturation stage resulted a small change in NTB estimations. The average NTBs of the reproductive and maturation stages were $0.7^{\circ} \mathrm{C}$ and $0.8^{\circ} \mathrm{C}$, with a rise of $0.1^{\circ} \mathrm{C}$. Taghvaeian et al. [42,67] also showed a negligible variation when to estimate maize NTB in northern Colorado.

$$
\begin{aligned}
& d T_{L L}=-2.64 \times V P D+0.42 \quad\left(R^{2}=0.89\right) \\
& d T_{L L}=-3.35 \times V P D+2.96\left(R^{2}=0.98\right)
\end{aligned}
$$

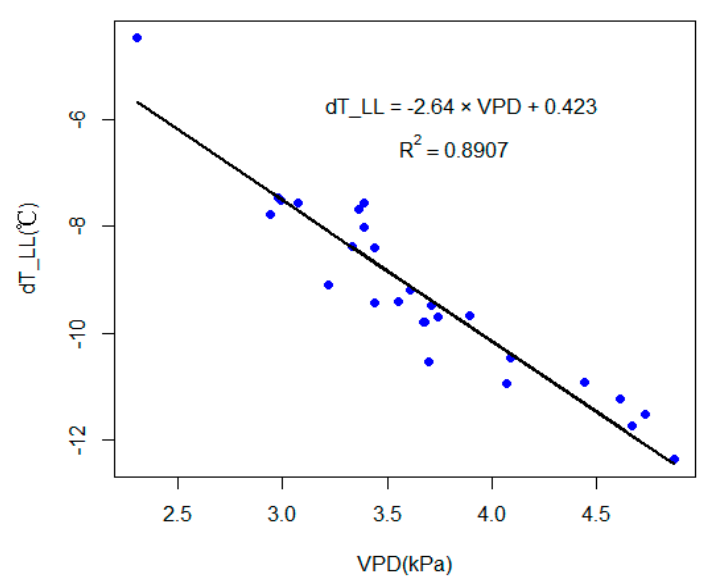

(a)

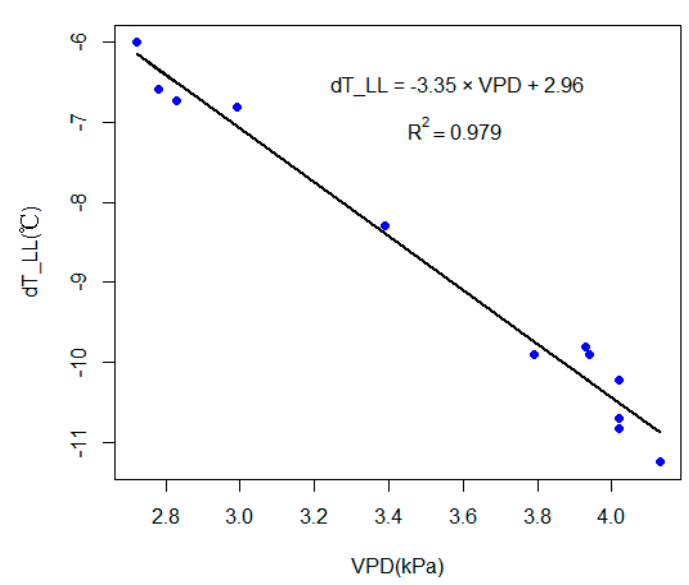

(b)

Figure 5. Maize non-water-stressed baselines (NWSBs) developed in this study during the reproductive (a) and maturation stages (b) in 2017. 


\subsection{CWSI of Maize}

Finally, the CWSI empirical model was obtained by using Tc, Ta_f and RH_f collected in the sampling plot. Figure 6 depicts the daily changes of CWSI and irrigation/rainfall events for the TRT 1 (Figure 6a) and TRT 4 (Figure 6b) during 2017.08.06 29. CWSI decreased after irrigation/rainfall, reached a minimum around the third day and then slowly increased, responding well to irrigation/rainfall events. When irrigation/rainfall was less, no more than $4 \mathrm{~mm}$, CWSI did not change significantly. The average CWSI for the different levels of deficit irrigation in the reproductive and maturation stages had a clear numerical gradient (Table 4). For example, the average CWSI was 0.11 and 0.27 for TRT 1 and TRT 4 in the reproductive stage, respectively. The average CWSI was 0.03, 0.14 and 0.32 for TRT 1 , TRT 2 , and TRT 4 in the maturation stage, respectively.

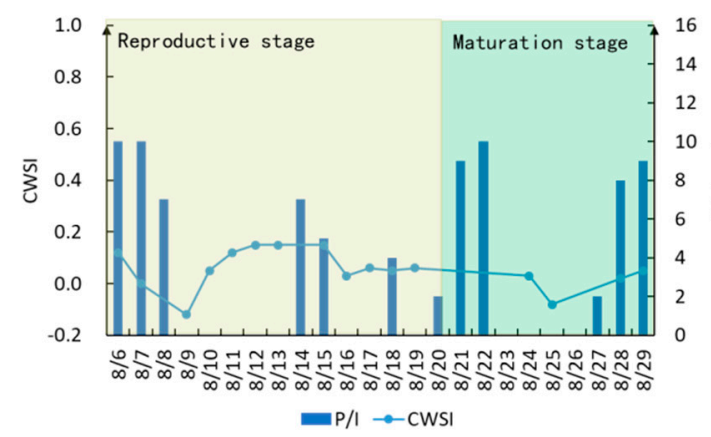

(a)

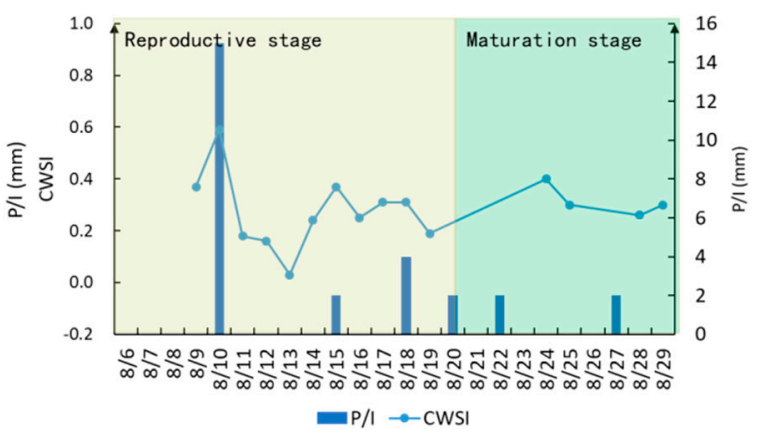

(b)

Figure 6. CWSI changing curves for TRT 1 (a) and TRT 4 (b) during 2017.08.06 29. The depths (mm) of individual irrigation (I) and precipitation (P) events were plotted as vertical bars.

Table 4. Mean CWSI for each deficit irrigation treatment during the reproductive and maturation stages in 2017.

\begin{tabular}{ccc}
\hline Treatment & Reproductive (08.06-08.20) & Maturation (08.21-08.29) \\
\hline TRT 1 & 0.07 & 0.03 \\
TRT 2 & 0.12 & 0.14 \\
TRT 3 & 0.09 & 0.12 \\
TRT 4 & 0.27 & 0.32 \\
TRT 5 & 0.05 & 0.03 \\
\hline
\end{tabular}

\subsection{Vegetation Indices}

Figure 7 shows the changes of NDVI, RDVI, SAVI, OSAVI, TCARI, TCARI/NDVI, TCARI/RDVI, TCARI/SAVI, and TCARI/OSAVI during DOY 171-241 (20 June-29 August 2017). Since NDVI, RDVI, SAVI, and OSAVI were closely related to the canopy structure; they increased with the growth of maize and reached the maximum on DOY 207 (26 July), decreased with the gradual maturity of maize. Previous studies showed that maize reaches full cover at a SAVI value of 0.64 [42,71]. SAVI of each deficit irrigation region was greater than 0.61 on DOY 207 , meaning maize canopy had reached effective coverage. NDVI had the slowest decline rate and the other three VIs were relatively close. Before the effective coverage of canopy (DOY 207), NDVI, RDVI, SAVI, and OSAVI did not effectively distinguish deficit irrigation treatments. For example, During DOY 185 (the start of deficit irrigation) to 206, the RDVI values of TRT 1 , TRT 3 and TRT 5 were $0.76,0.74$ and 0.73 , respectively, with small difference no more than 0.03 . The RDVI values of TRT 2 and TRT 4 were 0.69 and 0.67 with a small difference of 0.02 . There was clear difference between TRT 3 and TRT 4 that had the same deficit irrigation level (84\%) with a difference value of 0.07 . However, when the canopy reached effective coverage, NDVI, RDVI, SAVI, and OSAVI started to show obvious differences between different deficit irrigation treatments, especially in the maturation stage. For example, during the maturation stage 
(DOY233 241), the RDVI values of TRT1 and TRT5 (100\%), TRT2 and TRT3 (52\%), and TRT4 (28\%) were 0.54 and $0.54,0.52$ and 0.51 , and 0.47 , respectively. There was a clear numerical gradient among different levels of deficit irrigation treatments.
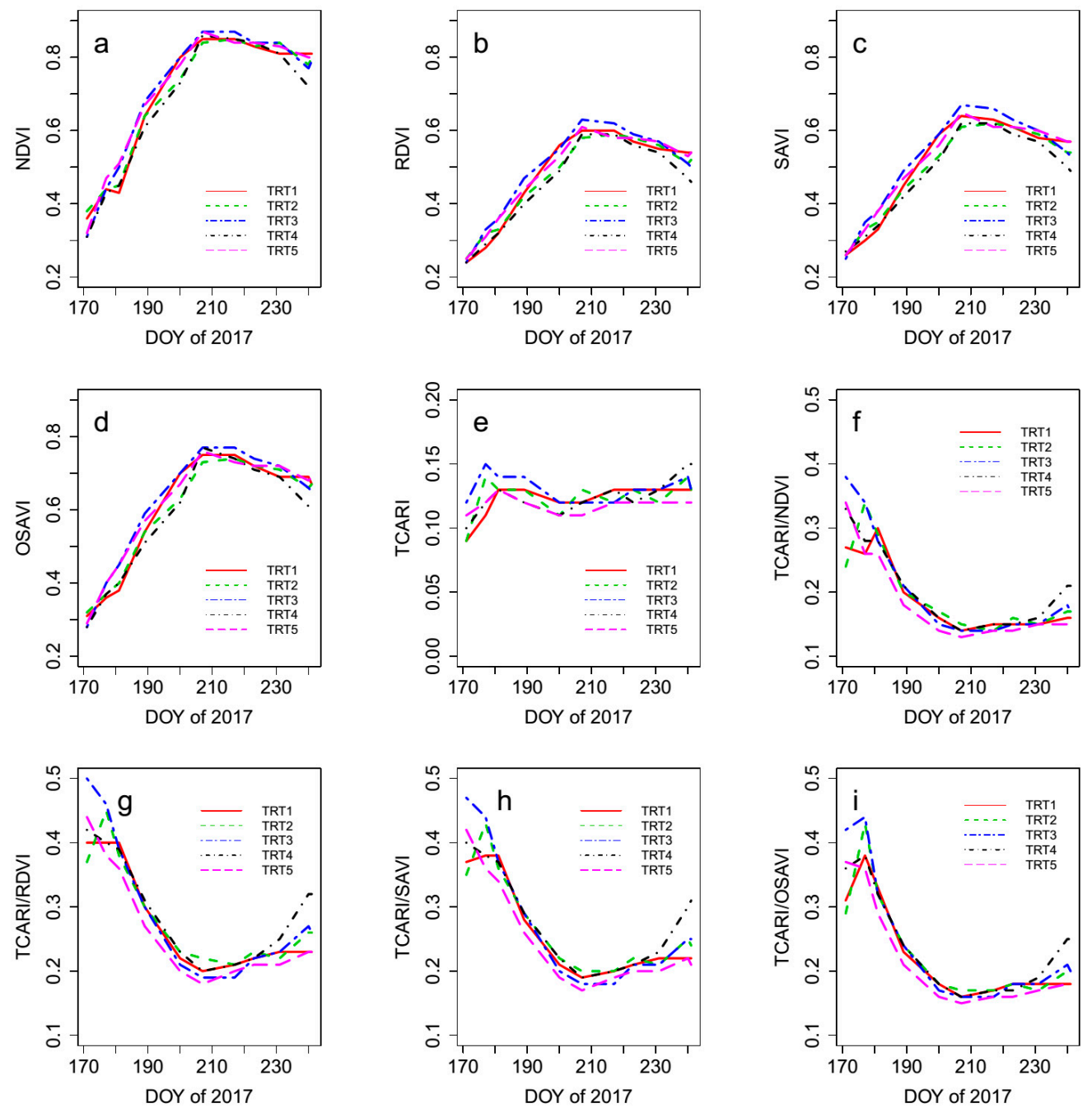

Figure 7. Changes of nine vegetation indices (VIs): normalized difference vegetation index (NDVI) (a), renormalized difference vegetation index (RDVI) (b), soil-adjusted vegetation index (SAVI) (c), optimization of soil-adjusted vegetation index (OSAVI) (d), transformed chlorophyll absorption in reflectance index (TCARI) (e), TCARI/NDVI (f), TCARI/RDVI (g), TCARI/SAVI (h), and TCARI/OSAVI (i), during DOY 171-241 (20 June, 20-29 August) for all deficit irrigation treatments. DOY is the abbreviation for day of year. The red, green, blue, black and pink lines represent the TRTs $1 \sim 5$, respectively.

In the case of TCARI, there were no significant changes during DOY 171-241. At the late reproductive and maturation stages (DOY 231-241), different levels of deficit irrigation treatments could be distinguished gradually by TCARI. Similar to NDVI, RDVI, SAVI, and OSAVI, TCARI/NDVI, TCARI/RDVI, TCARI/SAVI and TCARI/OSAVI which normalized by NDVI, RDVI, SAVI and OSAVI, changed with the growth of maize, reached minimum when the canopy reached effective coverage (DOY 207), and then slowly increased. Before the canopy reached effective coverage, they could not effectively distinguished water stress. However, when canopy reached effective coverage, they started to distinguish deficit irrigation treatments gradually. 


\subsection{Correlations between Vegetation Indices (VIs) and CWSI}

Table 5 shows a description of correlations between nine VIs and CWSI (corresponding scatter plots are shown in Figures A2 and A3). When VIs and CWSI data from four days (DOY 223, 231, 240 and 241) in the reproductive and maturation stages were used to perform linear regression analysis, $\mathrm{R}^{2}$ were all less than 0.50 . Among the four canopy structure VIs, NDVI had the best relationship $\left(\mathrm{R}^{2}=0.34, p<0.01\right)$. In the case of the five chlorophyll-related VIs, they all had a relatively better correlation (all $\mathrm{R}^{2}$ were greater than 0.35). Both TCARI/RDVI and TCARI/SAVI had significant correlation with CWSI $(p<0.001)$ and $\mathrm{R}^{2}$ were greater than 0.47 . When VIs and CWSI data from three days (DOY 231, 240 and 241) in the late reproductive and maturation stages were used, the correlations were significantly improved except for TCARI. All $\mathrm{R}^{2}$ were greater than $0.68(p<0.001)$. TCARI/RDVI and TCARI/SAVI had the best relationship (both $\mathrm{R}^{2} \geq 0.80, p<0.001$ ) Therefore, this paper choose TCARI/RDVI and TCARI/SAVI to establish linear regression models between VI and CWSI. To rescale the CWSI value between 0 and 1, the linear regression models were shown as Equations (14) and (15), respectively.

$$
\begin{gathered}
\text { CWSI }-1=\left\{\begin{array}{cc}
0 & (T C A R I / R D V I \leq 0.195) \\
2.41 *(T C A R I / R D V I)-0.47 & (0.195<T C A R I / R D V I<0.609) \\
1 & (0.609 \leq T C A R I / R D V I)
\end{array}\right. \\
\text { CWSI }-2=\left\{\begin{array}{cc} 
& (T C A R I / S A V I \leq 0.182) \\
2.46 *(T C A R I / S A V I)-0.45 & (0.182<\text { TCARI } / \text { SAVI }<0.589) \\
1 & (0.589 \leq T C A R I / S A V I)
\end{array}\right.
\end{gathered}
$$

Table 5. Coefficient of determination $\left(R^{2}\right)$, root mean square error (RMSE) from different predictions with CWSI vs. nine VIs based on VIs and CWSI data from three (DOY 231, 240 and 241) or four (DOY $223,231,240$ and 241) days.

\begin{tabular}{ccccc}
\hline \multirow{2}{*}{ Vegetation Index } & \multicolumn{2}{c}{ Three Corresponding Data } & \multicolumn{2}{c}{ Four Corresponding Data } \\
\cline { 2 - 5 } & $\mathbf{R}^{\mathbf{2}}(\boldsymbol{n}=\mathbf{1 5})$ & $\mathbf{R M S E}$ & $\mathbf{R}^{\mathbf{2}}(\boldsymbol{n}=\mathbf{2 0 )}$ & $\mathbf{R M S E}$ \\
\hline Structural & $0.72^{* * *}$ & 0.046 & $0.34^{* *}$ & 0.063 \\
NDVI & $0.81^{* * *}$ & 0.038 & $0.29^{*}$ & 0.065 \\
RDVI & $0.81^{* * *}$ & 0.037 & $0.27^{*}$ & 0.066 \\
SAVI & $0.74^{* * *}$ & 0.044 & $0.29^{*}$ & 0.065 \\
OSAVI & & & & \\
Chlorophyll & $0.55^{* *}$ & 0.058 & $0.35^{* *}$ & 0.062 \\
TCARI & $0.69^{* * *}$ & 0.048 & $0.42^{* *}$ & 0.059 \\
TCARI/NDVI & $0.81^{* * *}$ & 0.037 & $0.47^{* * *}$ & 0.056 \\
TCARI/RDVI & $0.80^{* * *}$ & 0.039 & $0.50^{* * *}$ & 0.055 \\
TCARI/SAVI & $0.77^{* * *}$ & 0.041 & $0.46^{* *}$ & 0.057 \\
TCARI/OSAVI & $* p<0.05 ; * * 0.01^{* * *} p<0.001$. &
\end{tabular}

\subsection{Maize Water Stress Maps Based on UAV Multispectral Remote-Sensing Imagery}

Equations (14) and (15) were used to retrieve maize water stress maps based on UAV TCARI/RDVI and TCARI/SAVI maps (Figure 8) for the reproductive (DOY 231) and maturation (DOY 240) stages. Table 6 shows the comparison of CWSI values (at DOY 231 and DOY 240) using two different methods. In the first method, CWSI values were calculated by on-site measurements within each sampling plot, and in the second method, CWSI values, CWSI- 1 and CWSI-2, retrieved from CWSI vs. VI regression models (Equations (14) and (15)). The value of CWSI- 1 and CWSI-2 was the average value of the entire treatment region. 


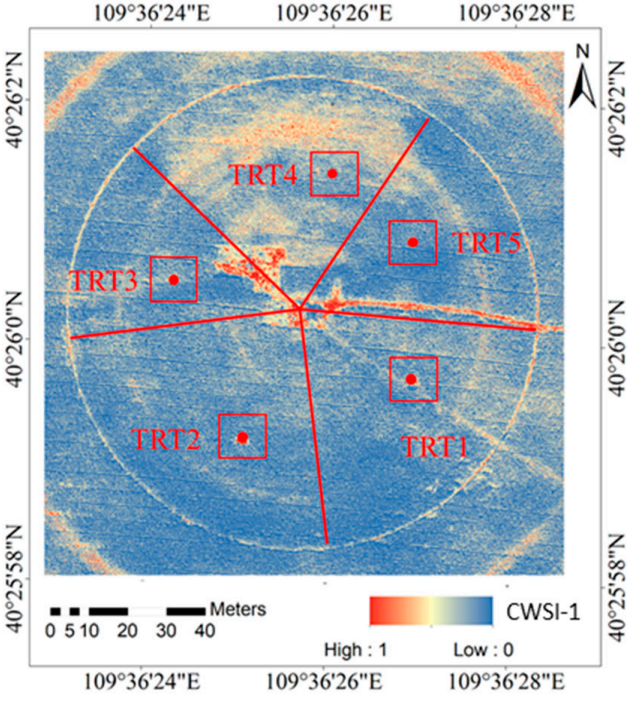

(a)

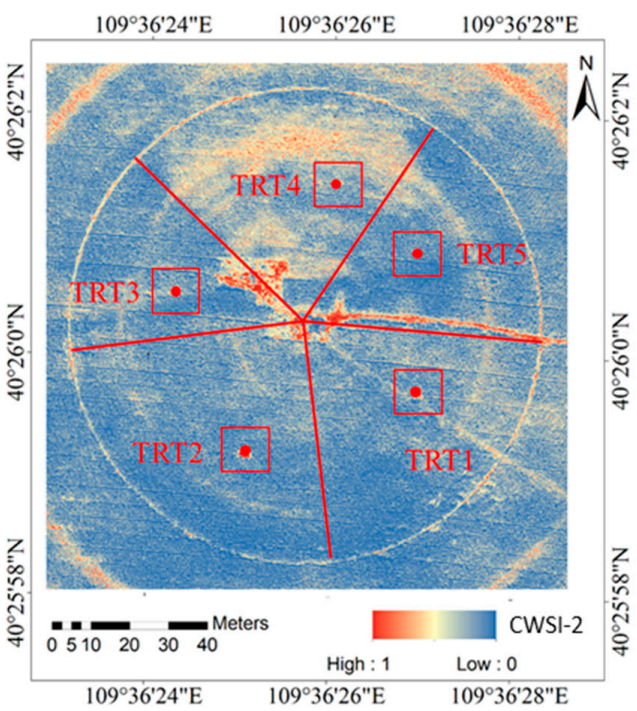

(c)

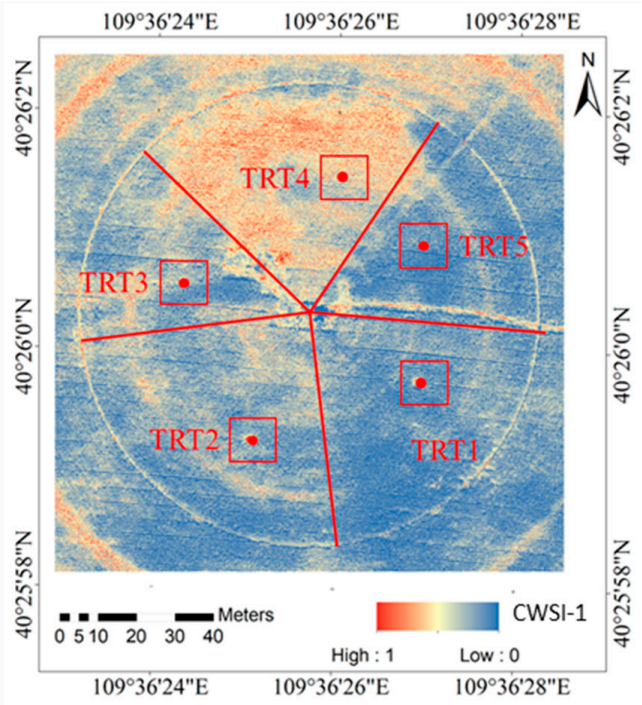

(b)

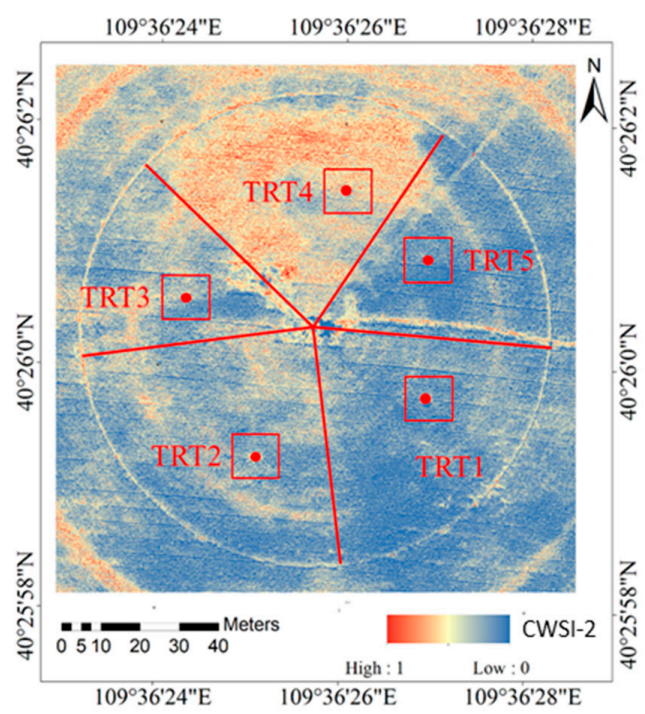

(d)

Figure 8. Maize water stress maps retrieved by CWSI vs. VI regression models (Equations (14) and (15)). (a,b) are water stress maps retrieved by Equation (14) for the reproductive (DOY 231) and maturation (DOY 240) stages, respectively. (c,d) are water stress maps retrieved by Equation (15) for the reproductive (DOY 231) and maturation (DOY 240) stages, respectively.

Table 6. Comparison of CWSI values (at DOY 231 and DOY 240) using two different methods. (1) CWSI values calculated by on-site measurements within each sampling plot, and (2) CWSI values retrieved from CWSI vs. VI regression models (Equations (14) and (15)). CWSI-1 and CWSI-2 were the average value of the entire treatment region.

\begin{tabular}{ccccccc}
\hline \multirow{2}{*}{ Treatment } & \multicolumn{3}{c}{ Reproductive (DOY 231) } & \multicolumn{3}{c}{ Maturation (DOY 240) } \\
\cline { 2 - 7 } & CWSI & CWSI-1 & CWSI-2 & CWSI & CWSI-1 & CWSI-2 \\
\hline TRT 1 & 0.06 & 0.09 & 0.09 & 0.02 & 0.11 & 0.11 \\
TRT 2 & 0.04 & 0.08 & 0.08 & 0.20 & 0.18 & 0.18 \\
TRT 3 & 0.05 & 0.09 & 0.09 & 0.14 & 0.23 & 0.22 \\
TRT 4 & 0.19 & 0.19 & 0.18 & 0.26 & 0.40 & 0.39 \\
TRT 5 & 0.04 & 0.08 & 0.08 & 0.10 & 0.13 & 0.12 \\
\hline
\end{tabular}




\section{Discussion}

Previous research has reported that one of the drawbacks of CWSI empirical model was the variability of NWSB [26,48,72,73]. Idso et al., (1981) reported that different crops had their own unique NWSBs. Even for the same crop, NWSB will consequently change at different locations. For instance, the slopes of maize NWSBs established at different locations vary from -1.10 to $-3.77^{\circ} \mathrm{C} / \mathrm{kPa}$, and the corresponding intercepts vary from 0.42 to $3.11^{\circ} \mathrm{C}$. Most previous researchers ascribe this change to the following factors:

(1) Climate variables [45,74-76], such as radiation and wind speed;

(2) Ta, RH measurement sitting [28,67,72], for example, Taghvaeian et al. [43] found that if Ta and $\mathrm{RH}$ sensor was installed at full irrigation region, larger NWSB for sunflower would have been assigned to deficit irrigation region;

(3) Tc monitoring instrument and its measure method [26,72];

(4) Specific hybrid differences [72,73], but previous studies have also suggested that the same NWSBs can be used for similar varieties of maize [67] and wheat [77].

Many previous researchers have also observed that the coefficients of NWSB among annual crops will change in different grown stages, such as maize, wheat, barley and sunflower. Idso et al. [69] reported that the NWSBs of wheat and barley shifted significantly, as they move from the vegetative to reproductive stage. The change of wheat and barley NWSBs was ascribed to the seed-heads that absorbed the radiant energy, converted it into sensible heat, and provided a very effective aerodynamic barrier against the transfer of sensible heat to the transpiring surfaces. Taghvaeian et al. [43] and Nielsen [68] also observed significant differences in the coefficients of sunflower NWSBs during the reproductive and maturation stages. The difference of sunflower NWSBs was attributed to the decrease in sunflower transpiration and increase in head temperature after sunflower transitioned into maturation stage. A similar observation was made by this study when to establish NWSBs for maize during the reproductive and maturation stages.

When trying to explain the difference of NWSBs among annual crops in different grown stages, previous researchers focused on the change of crop physiological characteristics, but ignored the change of microclimate, such as Ta and RH. In this study, compared to the reproductive stage, the average daily maximum temperature in the maturation stage decreased from $31.31{ }^{\circ} \mathrm{C}$ to $25.46^{\circ} \mathrm{C}$ and average daily minimum relative humidity increased from $29.78 \%$ to $33.23 \%$, with a decrease of $5.85{ }^{\circ} \mathrm{C}$ and an increase of $3.45 \%$, respectively (Table 2 ). The average daily maximum temperature and average daily minimum relative humidity had a similar changing trend in the study of Taghvaeian et al. [43]. Figure 9a shows the changing trend of VPD along with Ta and RH. The increase of RH and decrease of Ta will lead to a decrease of VPD. This result will lead to a decrease in transpiration rate of crops under well-watered conditions, which means the difference between Tc and Ta will lower. In other words, the decrease in VPD will lead to an increase in NWSB. In this study, compared to the reproductive stage, VPD decreased in the maturation stage with average value of $0.8 \mathrm{kPa}$, and NWSB increased with average value of $2.1^{\circ} \mathrm{C}$.

In general terms, plants under well irrigation condition have specific non-water stress lines that corresponding to average CWSI values. Previous studies about the use of the CWSI as a water stress indicator in olive and vineyards orchards have indicated that average CWSI in a well irrigation condition was less than $0.5[4,16,40,78]$. For maize, in this study, average CWSI values were no more than 0.12 in the reproductive stage, and a much smaller average CWSI, a value of 0.03 , in the maturation stage. An interesting result could be found that average CWSI value for maize under full irrigation condition, the non-water stress line, was much smaller, compared to the reproductive stage. The same average CWSI calculated by on- site measurements represented more serious water stress in the maturation stage than the reproductive stage. For example, the average CWSI of TRT 2 in the reproductive stage was 0.12 , while the average CWSI of TRT 3 in the maturation stage was also 0.12 , with $45 \%$ water applied difference. The average CWSI of TRT 4 in the reproductive stage was 0.27 , 
while the average CWSI of TRT 4 in the maturation stage was $0.32 .43 \%$ water applied difference corresponded to a 0.05 difference of CWSI value. Similar phenomenon had been observed by Han Ming et al. [26] for maize in Greeley, CO, USA. In the reproductive stage, average CWSI values were no more than 0.16 , and 0.5 in the maturation stage. This phenomenon may be explained in two ways:

(1) The change of maize physiological characteristics and microclimate from the reproductive to the maturation stage causes significant difference in NWSBs and insignificant difference in NTBs.

(2) The crop and soil characteristics in the field have significant variability in each deficit irrigation treatment regions. One sample plot could not represent the entire treatment region well (Figure 8). Santesteban et al. [79] had also found that an 18-year-old vineyard under same irrigation condition and without significant pets and diseases had significant variability in water status.

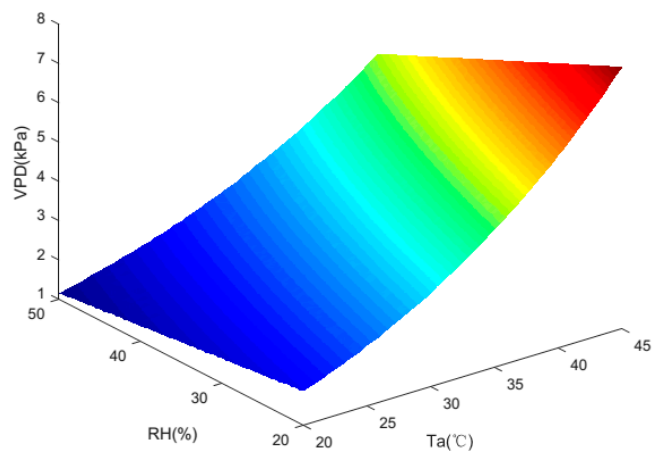

(a)

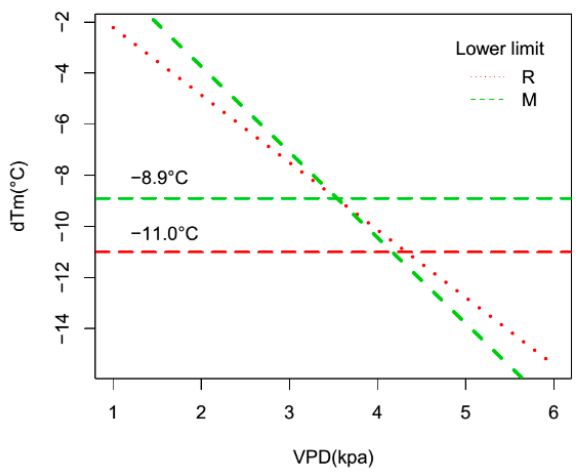

(b)

Figure 9. Vapor pressure deficit (VPD) changing trend along with Ta and RH (a); Changes of NWSB between the reproductive and maturation stages $(\mathbf{b})$.

Previous studies in the vineyard have indicated that multispectral VIs acquired from remote-sensing images have a significantly high correlation with water stress indicators, revealing the potential to assess water stress and its variability by using multispectral VIs. Espinoza et al. [80] found a high correlation $(\mathrm{r}=0.65, p<0.01)$ between GNDVI and stomatal conductance. Baluja et al. [81] found a $\mathrm{R}^{2}$ value of $0.68(n=10)$ from the linear regression between NDVI and stem water

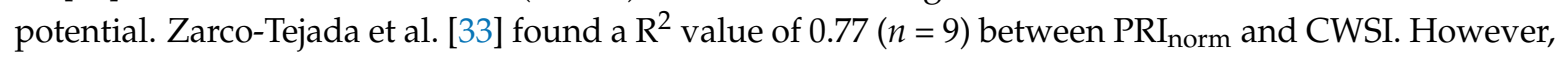
the relationship between UAV multispectral VIs and CWSI is not well documented for maize.

In this study, a higher significantly correlation between VIs acquired from UAV multispectral images and CWSI was found. In particular, compared to CWSI, the $\mathrm{R}^{2}$ values of TCARI/RDVI and TCARI/SAVI were 0.81 and $0.80(n=15)$ in the late reproductive and maturation stages. A similar observation was made by Baluja et al. [81] in a commercial vineyard, with the $\mathrm{R}^{2}$ values of TCARI/OSAVI were 0.58 and $0.84(n=10)$ compared to stem water potential and stomatal conductance, respectively. The results showed that TCARI/OSAVI were probably reflecting the result of cumulative water deficits, and hence a long-term response. In this study similar results were found, namely, when using UAV multispectral VIs to estimate maize water stress, their effects was influenced by the extended period of water stress. With the prolongation of water stress, UAV multispectral VIs could better distinguish different levels of deficit irrigation treatments (Figure 7). A similar phenomenon was also found by Espinoza et al. [80], Li et al. [82] and Zulini et al. [83]. Perhaps, this could explain that the $\mathrm{R}^{2}$ values of VIs-CWSI were higher in the late reproductive and maturation stages (DOY 231, 240 and 241) than in the reproductive and maturation stages (DOY 223, 231, 240 and 241) (Table 5). However, Zarco-Tejada et al. [84] found that TCARI/OSAVI was less correlated with leaf stomatal conductance and water potential in Citrus orchards, with the $\mathrm{R}^{2}$ values of 0.45 and 0.51 . The reason for the different observations might be that TCARI/OSAVI are more related to plant vigor than the plant dynamic physiological status, with the result that it might correlate well in crops where the biomass 
proportionally increases in parallel to photosynthesis, however, in the case of evergreen crop species, results were not so satisfactory [85].

TCARI/OSAVI, similar to TCARI/RDVI and TCARI/SAVI in this study, was established by Haboudane et al. [60] to make accurate predictions of maize chlorophyll content from hyperspectral remote-sensing imagery in Canada. The results showed that TCARI/OSAVI was both very sensitive to chlorophyll content variations and very resistant to the variations of leaf area index (LAI). The results of Zarco-Tejada et al. [86] in vineyard showed that TCARI/OSVAI was also correlated with xanthophyll and the carotenoid content with $\mathrm{R}^{2}$ value of $0.51(p<0.01)$. Under water stress condition, transpiration rate of crop may reduce, resulting a reduction of cooling effect $[87,88]$. To avoid damage to the tissues, crops need to reduce the absorption of light and dissipate the extra energy through the reduction of chlorophyll $\mathrm{b}$ and the interconversion of the xanthophyll cycle pigments, respectively [89]. Therefore, the correlations of TCARI/OSAVI with chlorophyll and xanthophyll content may be the crop physiological basis of why TCARI/OSAVI family of indices could monitor crop water stress status. Future, related research is still needed.

From the CWSI maps retrieved by TCARI/RDVI and TCARI/SAVI, we could find that the water stress status of maize in each irrigation treatment had spatial variations. Compared to CWSI calculated by on-site measurements, CWSI based on VI-CWSI regression models could better reflect water stress conditions of maize in the field scale. Taking CWSI-2 as an example, the average CWSI-2 could reflect TRT $4(69 \%)$ and TRT $1(100 \%)$ in the reproductive stage, with the values of 0.18 and 0.09 , respectively; and could reflect TRT4 (28\%), TRT2 and TRT3 (52\%), and TRT1 (100\%) in the maturation stage, with the value of $0.39,0.18$ and 0.22 , and 0.11 , respectively. Compared with CWSI calculated by on-site measurements, CWSI-2 was more reasonable (Table 6).

\section{Conclusions}

As one of the most important remote-sensing platforms, an unmanned aerial vehicle (UAV) system could obtain key information (e.g., water stress status) about a crop at high temporal frequency (1-3 days revisit) and high spatial resolution (centimeter scale). This study investigated whether a UAV-based multispectral remote sensing system could map the water stress status of maize at a farm scale, as a supplement to ground-based empirical crop water stress index (CWSI) model. Since, the local weather condition and management practices can greatly influence the applicability of the empirical CWSI model, changes of the non-water stress baseline (NWSB) and the non-transpiring baseline (NTB) were also analyzed. Our results confirmed that NWSB had a significant difference in the reproductive and maturation stages, however NTB did not change significantly. The shift of NWSB from the reproductive to maturation stage is not only related to the change of maize characteristics (e.g., canopy structure and transpiration rate), but also related to the change of microclimate, such as air temperature and relative humidity. The ratio of transformed chlorophyll absorption in the reflectance index (TCARI) and renormalized difference vegetation index (RDVI), and the TCARI and soil-adjusted vegetation index (SAVI) had high correlations with CWSI. $\mathrm{R}^{2}$ values were 0.47 and 0.50 for TCARI/RDVI at the reproductive and maturation stages, respectively; and 0.81 and 0.80 for TCARI/SAVI at the late reproductive and maturation stages, respectively. This study demonstrates the feasibility of mapping maize crop water status and monitoring its spatial variability at a farm scale by using UAV-based multispectral VI-CWSI regression models established in this study. As a future work, research into the influence of other meteorological parameters (e.g., extreme illumination) on the water stress monitoring effect of CWSI will be conducted. What changes of crop physiological characteristics (e.g., the changes of chlorophyll and xanthophyll caused by photoprotection) enable the vegetation index (e.g., TCARI/SAVI) to be used to monitor the water stress status of maize will also be studied.

Author Contributions: L.Z. and W.H. conceived and designed the experiments; L.Z. and Y.N. analyzed the data; L.Z. and H.Z. discussed and drafted the manuscript. H.Z. and W.H. revised the manuscript and edited English language. All authors read and approved the final version. 
Funding: This study was supported by the National Key R \& D plan from the MOST of China (2017YFC0403203), the Synergetic Innovation of Industry-University-Research Cooperation Project plan from Yangling (2018CXY-23), the 111 Project (No.B12007) and the Key Discipline Construction Project of Northwest Agriculture and Forestry University (2017-C03).

Acknowledgments: We are grateful to Guomin Shao, Yi Wang and Guang Li for data collection.

Conflicts of Interest: No conflict of interest.

\section{Appendix A}

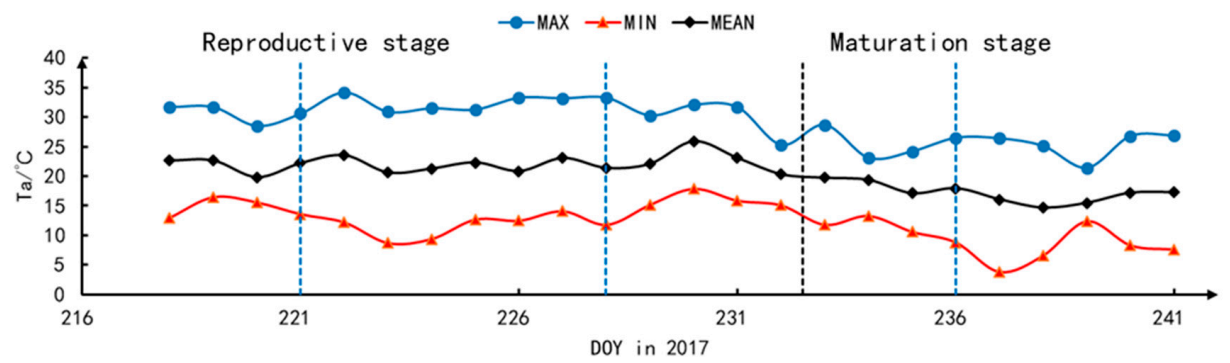

(a)

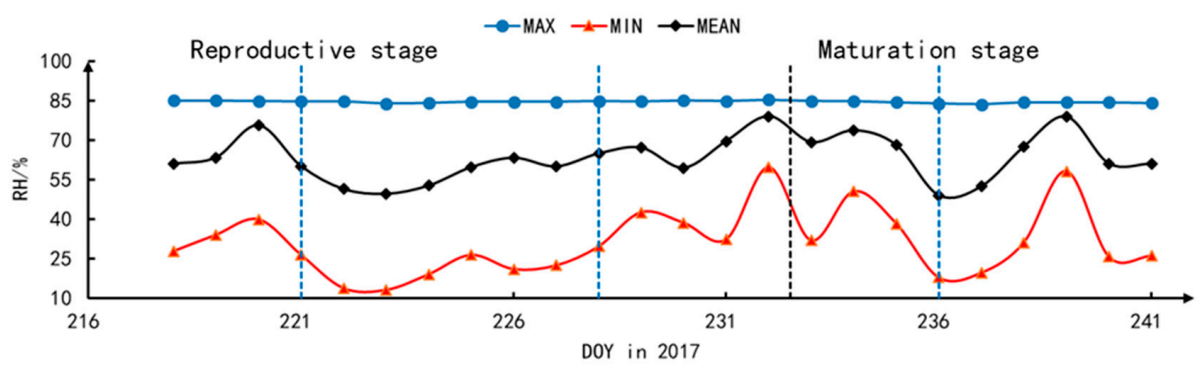

(b)

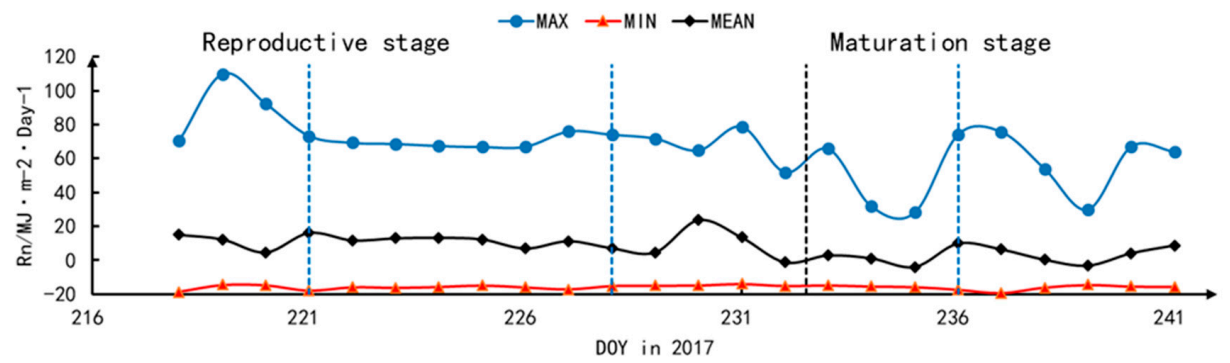

(c)

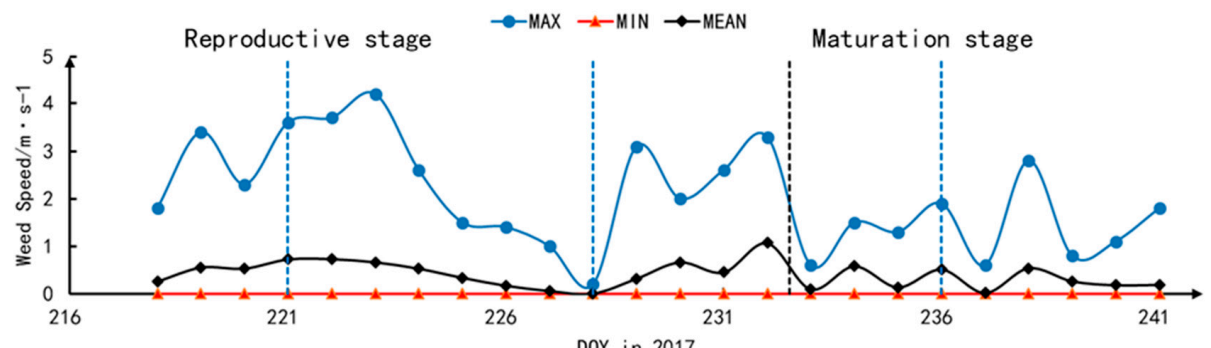

(d)

Figure A1. The changing curves of meteorological data during the reproductive and maturation stages in 2017. (a): air temperature (Ta); (b) relative humidity (RH); (c) net solar radiation (Rn); (d) weed speed. DOY is the abbreviation for day of year. The blue, red and black solid lines represent the maximum, minimum and mean values, respectively. The black dotted line is boundary between the reproductive and maturation stages. The blue dotted lines indicate dates when data was taken for the calculation of non-water-stressed and non-transpiring baselines of CWSI. 

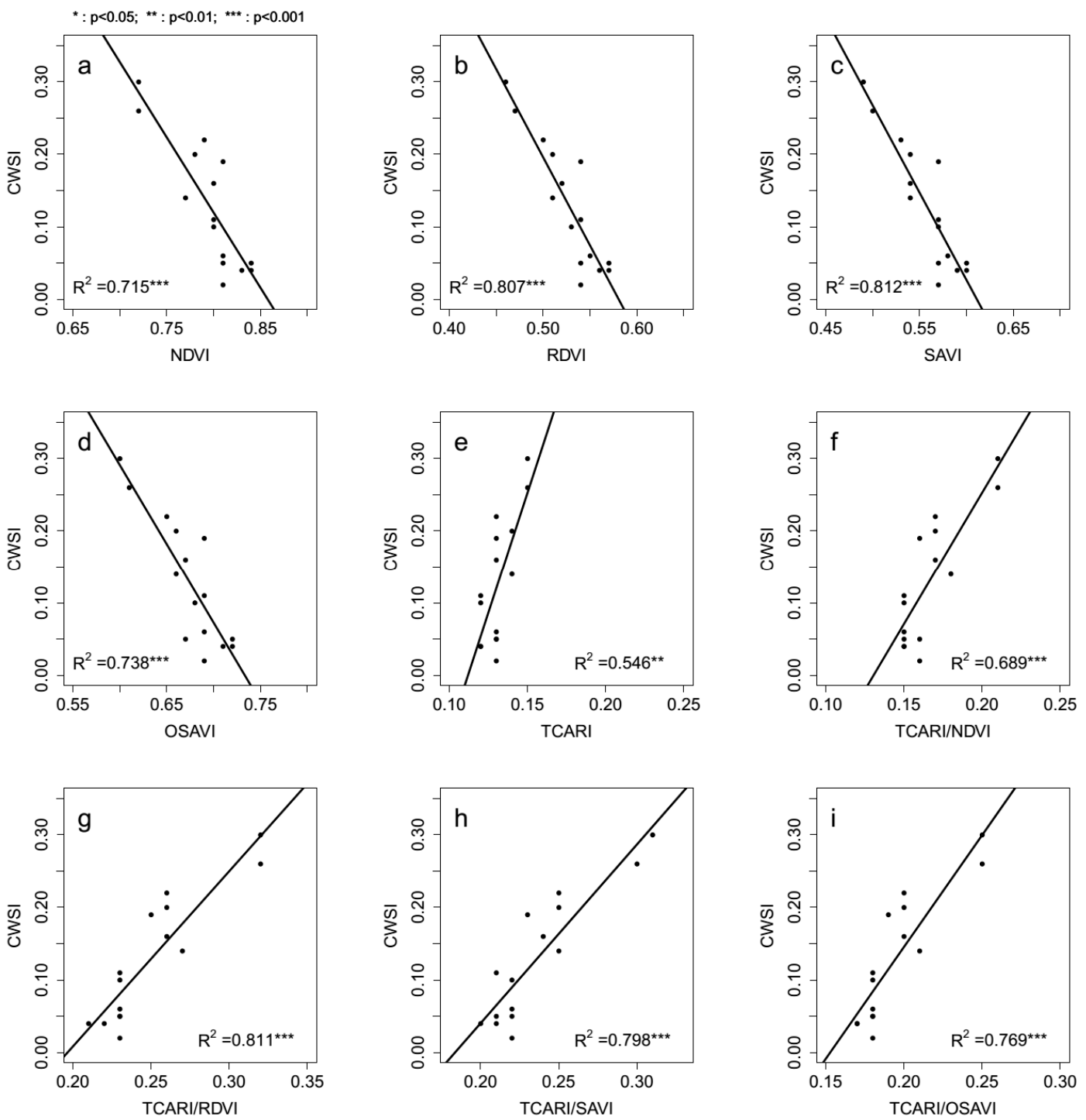

Figure A2. Correlations between unmanned aerial vehicle (UAV)-based multispectral VIs and CWSI based on three (DOY 231, 240 and 241) corresponding data. $R^{2}$ represents coefficient of determination. $p$ represents Pearson correlation coefficient. 

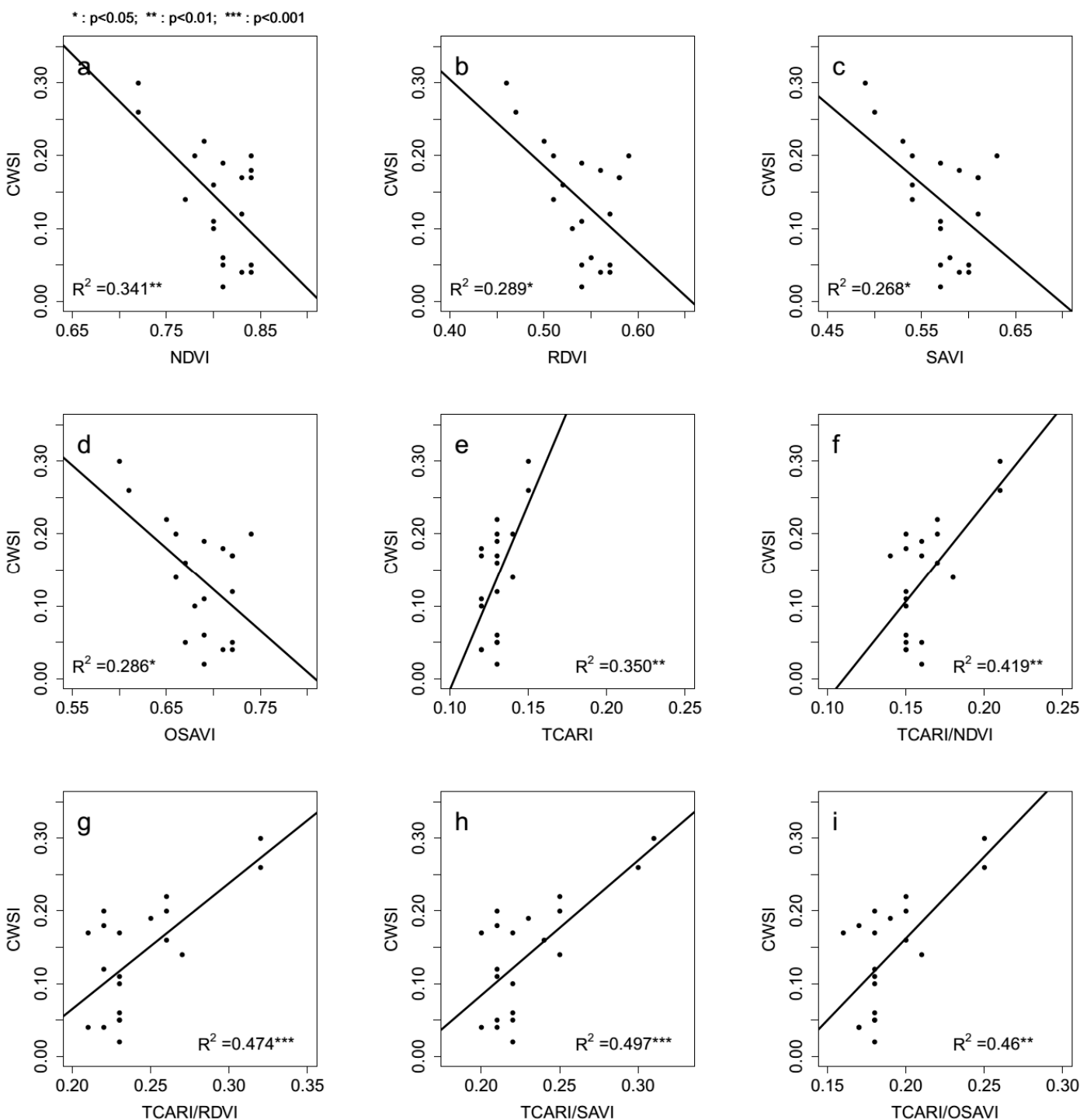

Figure A3. Correlations between UAV-based multispectral VIs and CWSI based on our (DOY 223, 231, 240 and 241) corresponding data. $\mathrm{R}^{2}$ represents coefficient of determination. $p$ represents Pearson correlation coefficient.

\section{References}

1. Lopez, J.R.; Winter, J.M.; Elliott, J.; Ruane, A.C.; Porter, C.; Hoogenboom, G. Integrating growth stage deficit irrigation into a process based crop model. Agric. For. Meteorol. 2017, 243, 84-92. [CrossRef]

2. Romero-Trigueros, C.; Nortes, P.A.; Alarcon, J.J.; Hunink, J.E.; Parra, M.; Contreras, S.; Droogers, P.; Nicolas, E. Effects of saline reclaimed waters and deficit irrigation on Citrus physiology assessed by UAV remote sensing. Agric. Water Manag. 2017, 183, 60-69. [CrossRef]

3. Zhao, T.B.; Stark, B.; Chen, Y.Q.; Ray, A.L.; Doll, D. A Detailed Field Study of Direct Correlations Between Ground Truth Crop Water Stress and Normalized Difference Vegetation Index (NDVI) from Small Unmanned Aerial System (sUAS). In Proceedings of the 2015 International Conference on Unmanned Aircraft Systems (ICUAS), Denver, CO, USA, 9-12 June 2015; pp. 520-525.

4. Sepulveda-Reyes, D.; Ingram, B.; Bardeen, M.; Zuniga, M.; Ortega-Farias, S.; Poblete-Echeverria, C. Selecting Canopy Zones and Thresholding Approaches to Assess Grapevine Water Status by Using Aerial and Ground-Based Thermal Imaging. Remote Sens. 2016, 8, 822. [CrossRef]

5. Cui, N.; Du, T.; Kang, S.; Li, F.; Zhang, J.; Wang, M.; Li, Z. Regulated deficit irrigation improved fruit quality and water use efficiency of pear-jujube trees. Agric. Water Manag. 2008, 95, 489-497. [CrossRef] 
6. Geerts, S.; Raes, D. Deficit irrigation as an on-farm strategy to maximize crop water productivity in dry areas. Agric. Water Manag. 2009, 96, 1275-1284. [CrossRef]

7. Han, M.; Zhang, H.; DeJonge, K.C.; Comas, L.H.; Trout, T.J. Estimating maize water stress by standard deviation of canopy temperature in thermal imagery. Agric. Water Manag. 2016, 177, 400-409. [CrossRef]

8. Ihuoma, S.O.; Madramootoo, C.A. Recent advances in crop water stress detection. Comput. Electron. Agric. 2017, 141, 267-275. [CrossRef]

9. Li, L.; Nielsen, D.C.; Yu, Q.; Ma, L.; Ahuja, L.R. Evaluating the Crop Water Stress Index and its correlation with latent heat and CO2 fluxes over winter wheat and maize in the North China plain. Agric. Water Manag. 2010, 97, 1146-1155. [CrossRef]

10. Campbell, G.S.; Campbell, M.D.J.A.i.I. Irrigation Scheduling Using Soil Moisture Measurements: Theory and Practice. Adv. Irrig. 1982, 1, 25-42. [CrossRef]

11. Hazaymeh, K.; Hassan, Q.K. Remote sensing of agricultural drought monitoring: A state of art review. Aims Environ. Sci. 2016, 3, 604-630. [CrossRef]

12. Calera, A.; Campos, I.; Osann, A.; D’Urso, G.; Menenti, M. Remote Sensing for Crop Water Management: From ET Modelling to Services for the End Users. Sensors 2017, 17, 1104. [CrossRef]

13. Du, L.; Tian, Q.; Yu, T.; Meng, Q.; Jancso, T.; Udvardy, P.; Huang, Y. A comprehensive drought monitoring method integrating MODIS and TRMM data. Int. J. Appl. Earth Obs. Geoinf. 2013, 23, 245-253. [CrossRef]

14. Helman, D.; Bahat, I.; Netzer, Y.; Ben-Gal, A.; Alchanatis, V.; Peeters, A.; Cohen, Y. Using Time Series of High-Resolution Planet Satellite Images to Monitor Grapevine Stem Water Potential in Commercial Vineyards. Remote Sens. 2018, 10, 1615. [CrossRef]

15. Zhang, H.; Han, M.; Chavez, J.L.; Lan, Y. Improvement in estimation of soil water deficit by integrating airborne imagery data into a soil water balance model. Int. J. Agric. Biol. Eng. 2017, 10, 37-46. [CrossRef]

16. Bellvert, J.; Marsal, J.; Girona, J.; Zarco-Tejada, P.J. Seasonal evolution of crop water stress index in grapevine varieties determined with high-resolution remote sensing thermal imagery. Irrig. Sci. 2015, 33, 81-93. [CrossRef]

17. Gerhards, M.; Schlerf, M.; Rascher, U.; Udelhoven, T.; Juszczak, R.; Alberti, G.; Miglietta, F.; Inoue, Y. Analysis of Airborne Optical and Thermal Imagery for Detection of Water Stress Symptoms. Remote Sens. 2018, 10, 1139. [CrossRef]

18. Bai, H.; Purcell, L.C. Aerial canopy temperature differences between fast- and slow-wilting soya bean genotypes. J. Agron. Crop Sci. 2018, 204, 243-251. [CrossRef]

19. Herwitz, S.R.; Johnson, L.F.; Dunagan, S.E.; Higgins, R.G.; Sullivan, D.V.; Zheng, J.; Lobitz, B.M.; Leung, J.G.; Gallmeyer, B.A.; Aoyagi, M.; et al. Imaging from an unmanned aerial vehicle: Agricultural surveillance and decision support. Comput. Electron. Agric. 2004, 44, 49-61. [CrossRef]

20. Han, W.; Zhang, L.; Zhang, H.; Shi, Z.; Yuan, M.; Wang, Z. Extraction Method of Sublateral Canal Distribution Information Based on UAV Remote Sensing. Nongye Jixie Xuebao/Trans. Chin. Soc. Agric. Mach. 2017, 48, 210-219. [CrossRef]

21. Han, W.; Guang, L.I.; Yuan, M.; Zhang, L.; Shi, Z. Extraction Method of Maize Planting Information Based on UAV Remote Sensing Techonology. Nongye Jixie Xuebao/Trans. Chin. Soc. Agric. Mach. 2017, 48, 139-147. [CrossRef]

22. Zhao, C. Advances of Research and Application in Remote Sensing for Agriculture. Nongye Jixie Xuebao/Trans. Chin. Soc. Agric. Mach. 2014, 45, 277-293. [CrossRef]

23. Inoue, Y.; Kimball, B.A.; Jackson, R.D.; Jr, P.J.P.; Reginato, R.J. Remote estimation of leaf transpiration rate and stomatal resistance based on infrared thermometry. Agric. For. Meteorol. 1990, 51, 21-33. [CrossRef]

24. Zhang, Z.; Bian, J.; Han, W.; Fu, Q.; Chen, S.; Cui, T. Cotton moisture stress diagnosis based on canopy temperature characteristics calculated from UAV thermal infrared image. Nongye Gongcheng Xuebao/Trans. Chin. Soc. Agric. Eng. 2018, 34, 77-84. [CrossRef]

25. Martínez, J.; Egea, G.; Agüera, J.; Pérez-Ruiz, M. A cost-effective canopy temperature measurement system for precision agriculture: A case study on sugar beet. Precis. Agric. 2016, 18, 95-110. [CrossRef]

26. Han, M.; Zhang, H.H.; DeJonge, K.C.; Comas, L.H.; Gleason, S. Comparison of three crop water stress index models with sap flow measurements in maize. Agric. Water Manag. 2018, 203, 366-375. [CrossRef]

27. Zia, S.; Romano, G.; Spreer, W.; Sanchez, C.; Cairns, J.; Araus, J.L.; Muller, J. Infrared Thermal Imaging as a Rapid Tool for Identifying Water-Stress Tolerant Maize Genotypes of Different Phenology. J. Agron. Crop Sci. 2013, 199, 75-84. [CrossRef] 
28. Zhang, L.; Niu, Y.; Han, W.; Liu, Z. Establishing Method of Crop Water Stress Index Empirical Model of Field Maize. Nongye Jixie Xuebao/Trans. Chin. Soc. Agric. Mach. 2018, 49, 233-239. [CrossRef]

29. Irmak, S.; Haman, D.Z.; Bastug, R. Determination of crop water stress index for irrigation timing and yield estimation of corn. Agron. J. 2000, 92, 1221-1227. [CrossRef]

30. Zhang, Z.; Bian, J.; Han, W.; Fu, Q.; Chen, S.; Cui, T. Diagnosis of Cotton Water Stress Using Unmanned Aerial Vehicle Thermal Infrared Remote Sensing after Removing Soil. Nongye Jixie Xuebao/Trans. Chin. Soc. Agric. Mach. 2018, 49, 250-260. [CrossRef]

31. Cohen, Y.; Alchanatis, V.; Sela, E.; Saranga, Y.; Cohen, S.; Meron, M.; Bosak, A.; Tsipris, J.; Ostrovsky, V.; Orolov, V.; et al. Crop water status estimation using thermography: Multi-year model development using ground-based thermal images. Precis. Agric. 2015, 16, 311-329. [CrossRef]

32. Pou, A.; Diago, M.P.; Medrano, H.; Baluja, J.; Tardaguila, J. Validation of thermal indices for water status identification in grapevine. Agric. Water Manag. 2014, 134, 60-72. [CrossRef]

33. Zarco-Tejada, P.J.; Gonzalez-Dugo, V.; Williams, L.E.; Suarez, L.; Berni, J.A.J.; Goldhamer, D.; Fereres, E. A PRI-based water stress index combining structural and chlorophyll effects: Assessment using diurnal narrow-band airborne imagery and the CWSI thermal index. Remote Sens. Environ. 2013, 138, 38-50. [CrossRef]

34. Agam, N.; Cohen, Y.; Alchanatis, V.; Ben-Gal, A. How sensitive is the CWSI to changes in solar radiation? Int. J. Remote Sens. 2013, 34, 6109-6120. [CrossRef]

35. Bellvert, J.; Zarco-Tejada, P.J.; Girona, J.; González-Dugo, V.; Fereres, E. A tool for detecting crop water status using airborne high-resolution thermal imagery. WIT Trans. Ecol. Environ. 2014, 185, 25-32.

36. Wang, D.; Gartung, J. Infrared canopy temperature of early-ripening peach trees under postharvest deficit irrigation. Agric. Water Manag. 2010, 97, 1787-1794. [CrossRef]

37. Paltineanu, C.; Septar, L.; Moale, C. Crop Water Stress in Peach Orchards and Relationships with Soil Moisture Content in a Chernozem of Dobrogea. J. Irrig. Drain. Eng. 2013, 139, 20-25. [CrossRef]

38. Agam, N.; Cohen, Y.; Berni, J.A.J.; Alchanatis, V.; Kool, D.; Dag, A.; Yermiyahu, U.; Ben-Gal, A. An insight to the performance of crop water stress index for olive trees. Agric. Water Manag. 2013, 118, 79-86. [CrossRef]

39. Gençğlan, C.; Yazar, A. Determination of Crop Water Stress İndex (CWSI) and irrigation timing by utilizing infrared thermometer values on the first corn grown under çukurova conditions. Am. J. Surg. 2014, 3, 342-345. [CrossRef]

40. Berni, J.A.J.; Zarco-Tejada, P.J.; Sepulcre-Canto, G.; Fereres, E.; Villalobos, F. Mapping canopy conductance and CWSI in olive orchards using high resolution thermal remote sensing imagery. Remote Sens. Environ. 2009, 113, 2380-2388. [CrossRef]

41. DeJonge, K.C.; Taghvaeian, S.; Trout, T.J.; Comas, L.H. Comparison of canopy temperature-based water stress indices for maize. Agric. Water Manag. 2015, 156, 51-62. [CrossRef]

42. Taghvaeian, S.; Chavez, J.L.; Hansen, N.C. Infrared Thermometry to Estimate Crop Water Stress Index and Water Use of Irrigated Maize in Northeastern Colorado. Remote Sens. 2012, 4, 3619-3637. [CrossRef]

43. Taghvaeian, S.; Comas, L.; DeJonge, K.C.; Trout, T.J. Conventional and simplified canopy temperature indices predict water stress in sunflower. Agric. Water Manag. 2014, 144, 69-80. [CrossRef]

44. Wang, L.M.; Qiu, G.Y.; Zhang, X.Y.; Chen, S.Y. Application of a new method to evaluate crop water stress index. Irrig. Sci. 2005, 24, 49-54. [CrossRef]

45. Gonzalez-Dugo, V.; Zarco-Tejada, P.J.; Fereres, E. Applicability and limitations of using the crop water stress index as an indicator of water deficits in citrus orchards. Agric. For. Meteorol. 2014, 198, 94-104. [CrossRef]

46. Ballester, C.; Jimenez-Bello, M.A.; Castel, J.R.; Intrigliolo, D.S. Usefulness of thermography for plant water stress detection in citrus and persimmon trees. Agric. For. Meteorol. 2013, 168, 120-129. [CrossRef]

47. Gonzalez-Dugo, V.; Goldhamer, D.; Zarco-Tejada, P.J.; Fereres, E. Improving the precision of irrigation in a pistachio farm using an unmanned airborne thermal system. Irrig. Sci. 2015, 33, 43-52. [CrossRef]

48. Idso, S.B.; Jackson, R.D.; Pinter, P.J., Jr.; Reginato, R.J.; Hatfield, J.L. Normalizing the stress-degree-day parameter for environmental variability. Agric. Meteorol. 1981, 24, 45-55. [CrossRef]

49. Jackson, R.D.; Idso, S.B.; Reginato, R.J.; Pinter, P.J. Canopy temperature as a crop water stress indicator. Water Resour. Res. 1981, 17, 1133-1138. [CrossRef]

50. Rodriguez-Perez, J.R.; Riano, D.; Carlisle, E.; Ustin, S.; Smart, D.R. Evaluation of hyperspectral reflectance indexes to detect grapevine water status in vineyards. Am. J. Enol. Vitic. 2007, 58, 302-317. 
51. Park, S.; Ryu, D.; Fuentes, S.; Chung, H.; Hernández-Montes, E.; O'Connell, M. Adaptive Estimation of Crop Water Stress in Nectarine and Peach Orchards Using High-Resolution Imagery from an Unmanned Aerial Vehicle (UAV). Remote Sens. 2017, 9, 828. [CrossRef]

52. Moran, M.S.; Clarke, T.R.; Inoue, Y.; Vidal, A. Estimating Crop Water-Deficit Using the Relation Between Surface-Air Temperature and Spectral Vegetation Index. Remote Sens. Environ. 1994, 49, 246-263. [CrossRef]

53. Wang, P.; Luo, X.; Zhou, Z.; Zang, Y.; Hu, L. Key technology for remote sensing information acquisitionbased on micro UAV. Nongye Gongcheng Xuebao/Trans. Chin. Soc. Agric. Eng. 2014, 30, 1-12. [CrossRef]

54. Xiang, H.; Tian, L. Development of a low-cost agricultural remote sensing system based on an autonomous unmanned aerial vehicle (UAV). Biosyst. Eng. 2011, 108, 174-190. [CrossRef]

55. Bellvert, J.; Zarco-Tejada, P.J.; Girona, J.; Fereres, E. Mapping crop water stress index in a 'Pinot-noir' vineyard: Comparing ground measurements with thermal remote sensing imagery from an unmanned aerial vehicle. Precis. Agric. 2014, 15, 361-376. [CrossRef]

56. Ribeiro-Gomes, K.; Hernandez-Lopez, D.; Ortega, J.F.; Ballesteros, R.; Poblete, T.; Moreno, M.A. Uncooled Thermal Camera Calibration and Optimization of the Photogrammetry Process for UAV Applications in Agriculture. Sensors 2017, 17, 2173. [CrossRef]

57. Ni, G. Vegetation Index and Its Advances. Arid Meteorol. 2003, 21, 71-75.

58. Rouse, J.W., Jr.; Haas, R.H.; Schell, J.A.; Deering, D.W. Monitoring Vegetation Systems in the Great Plains with Erts. Nasa Spec. Publ. 1973, 351, 309.

59. Huete, A.R. A soil-adjusted vegetation index (SAVI). Remote Sens. Environ. 1988, 25, 295-309. [CrossRef]

60. Driss, H.; John, R.M.; Nicolas, T.; Pablo, J.Z.-T.; Louise, D. Integrated narrow-band vegetation indices for prediction of crop chlorophyll content for application to precision agriculture. Remote Sens. Environ. 2002, 81, 416-426. [CrossRef]

61. Lv, Y.; Li, B. Soil Science; China Agriculture Press: Beijing, China, 2006.

62. Allen, R.G.; Pereira, L.S.; Raes, D.; Smith, M. Crop Evapotranspiration-Guidelines for Computing Crop Water Requirements—FAO Irrigation and Drainage Paper 56; FAO—Food and Agriculture Organization of the United Nations: Rome, Italy, 1998.

63. Li, Y.; Yan, H.; Cai, D.; Gu, T.; Sui, R.; Chen, D. Evaluating the water application uniformity of center pivot irrigation systems in Northern China. Int. Agric. Eng. J. 2018. under review.

64. Heermann, D.F.H.; Hein, P.R. Performance characteristics of self-propelled center-pivot sprinkler irrigation system. Trans. ASAE 1968, 11, 11-15.

65. Yang, G.; Li, C.; Yu, H.; Xu, B.; Feng, H.; Gao, L.; Zhu, D. UAV based multi-load remote sensing technologies for wheat breeding information acquirement. Nongye Gongcheng Xuebao/Trans. Chin. Soc. Agric. Eng. 2015, 31, 184-190. [CrossRef]

66. Walter, I.A.; Allen, R.G.; Elliott, R.; Jensen, M.E.; Itenfisu, D.; Mecham, B.; Howell, T.A.; Snyder, R.; Brown, P.; Echings, S. ASCE's standardized reference evapotranspiration equation. In Proceedings of the Watershed Management and Operations Management 2000, Fort Collins, CO, USA, 20-24 June 2000; pp. 1-11.

67. Taghvaeian, S.; Chávez, J.L.; Bausch, W.C.; DeJonge, K.C.; Trout, T.J. Minimizing instrumentation requirement for estimating crop water stress index and transpiration of maize. Irrig. Sci. 2014, 32, 53-65. [CrossRef]

68. Nielsen, D.C. Non water-stressed baselines for sunflowers. Agric. Water Manag. 1994, 26, 265-276. [CrossRef]

69. Idso, S.B. Non-water-stressed baselines: A key to measuring and interpreting plant water stress. Agric. Meteorol. 1982, 27, 59-70. [CrossRef]

70. Xiao, C.; Xu, L.; Yuan, G.; Wang, W.; Yi, L. Crop water stress index model for monitoring summer maize water stress based on canopy surface temperature. Trans. Chin. Soc. Agric. Eng. 2005, 21, 22-24. [CrossRef]

71. Bausch, W.C. Soil background effects on reflectance-based crop coefficients for corn. Remote Sens. Environ. 1993, 46, 213-222. [CrossRef]

72. Yazar, A.; Howell, T.A.; Dusek, D.A.; Copeland, K.S. Evaluation of crop water stress index for LEPA irrigated corn. Irrig. Sci. 1999, 18, 171-180. [CrossRef]

73. Gardner, B.R.; Nielsen, D.C.; Shock, C.C. Infrared thermometry and the crop water stress index. II. Sampling procedures and interpretation. J. Prod. Agric. 1993, 5, 466-475. [CrossRef]

74. Payero, J.O.; Irmak, S. Variable upper and lower crop water stress index baselines for corn and soybean. Irrig. Sci. 2006, 25, 21-32. [CrossRef]

75. Payero, J.O.; Neale, C.M.U.; Wright, J.L. Non-water-stressed baselines for calculating Crop Water Stress Index (CWSI) for alfalfa and tall fescue grass. Trans. ASAE 2005, 48, 653-661. [CrossRef] 
76. Zolnier, S.; Gates, R.S.; Anderson, R.G.; Nokes, S.E.; Duncan, G.A. Non-water-stressed baseline as a tool for dynamic control of a misting system for propagation of poinsettias. Trans. ASAE 2001, 44, 137-147. [CrossRef]

77. Idso, S.B.; Reginato, R.J.; Clawson, K.L.; Anderson, M.G. On the stability of non-water-stressed baselines. Agric. For. Meteorol. 1984, 32, 177-182. [CrossRef]

78. Ben-Gal, A.; Agam, N.; Alchanatis, V.; Cohen, Y.; Yermiyahu, U.; Zipori, I.; Presnov, E.; Sprintsin, M.; Dag, A. Evaluating water stress in irrigated olives: Correlation of soil water status, tree water status, and thermal imagery. Irrig. Sci. 2009, 27, 367-376. [CrossRef]

79. Santesteban, L.G.; Di Gennaro, S.F.; Herrero-Langreo, A.; Miranda, C.; Royo, J.B.; Matese, A. High-resolution UAV-based thermal imaging to estimate the instantaneous and seasonal variability of plant water status within a vineyard. Agric. Water Manag. 2017, 183, 49-59. [CrossRef]

80. Espinoza, C.Z.; Khot, L.R.; Sankaran, S.; Jacoby, P.W. High Resolution Multispectral and Thermal Remote Sensing-Based Water Stress Assessment in Subsurface Irrigated Grapevines. Remote Sens. 2017, 9, 961. [CrossRef]

81. Baluja, J.; Diago, M.P.; Balda, P.; Zorer, R.; Meggio, F.; Morales, F.; Tardaguila, J. Assessment of vineyard water status variability by thermal and multispectral imagery using an unmanned aerial vehicle (UAV). Irrig. Sci. 2012, 30, 511-522. [CrossRef]

82. Li, H.; Luo, Y.; Zhao, C.; Yang, G. Estimating crop coefficients of winter wheat based on canopy spectral vegetation indices. Nongye Gongcheng Xuebao/Trans. Chin. Soc. Agric. Eng. 2013, 29, 118-127. [CrossRef]

83. Zulini, L.; Rubinigg, M.; Zorer, R.; Bertamini, M. Effects of drought stress on chlorophyll fluorescence and photosynthetic pigments in grapevine leaves (Vitis vinifera cv. 'White Riesling'). Acta Horticulturae 2007, 754, 289-294. [CrossRef]

84. Zarco-Tejada, P.J.; Gonzalez-Dugo, V.; Berni, J.A.J. Fluorescence, temperature and narrow-band indices acquired from a UAV platform for water stress detection using a micro-hyperspectral imager and a thermal camera. Remote Sens. Environ. 2012, 117, 322-337. [CrossRef]

85. Gago, J.; Douthe, C.; Coopman, R.E.; Gallego, P.P.; Ribas-Carbo, M.; Flexas, J.; Escalona, J.; Medrano, H. UAVs challenge to assess water stress for sustainable agriculture. Agric. Water Manag. 2015, 153, 9-19. [CrossRef]

86. Zarco-Tejada, P.J.; Guillen-Climent, M.L.; Hernandez-Clemente, R.; Catalina, A.; Gonzalez, M.R.; Martin, P. Estimating leaf carotenoid content in vineyards using high resolution hyperspectral imagery acquired from an unmanned aerial vehicle (UAV). Agric. For. Meteorol. 2013, 171, 281-294. [CrossRef]

87. Sagan, V.; Maimaitiyiming, M.; Fishman, J. Effects of Ambient Ozone on Soybean Biophysical Variables and Mineral Nutrient Accumulation. Remote Sens. 2018, 10, 562. [CrossRef]

88. Urban, J.; Ingwers, M.W.; McGuire, M.A.; Teskey, R.O. Increase in leaf temperature opens stomata and decouples net photosynthesis from stomatal conductance in Pinus taeda and Populus deltoides x nigra. J. Exp. Bot. 2017, 68, 1757-1767. [CrossRef] [PubMed]

89. Zhang, J.; Cheng, D.; Li, Y.; Chen, H. Effect of Light and Water Stress on Photochemical Efficiency and Pigment Composition of Sabina vulgaris Seedlings. Chin. Bull. Bot. 2017, 53, 278-289. [CrossRef]

(C) 2019 by the authors. Licensee MDPI, Basel, Switzerland. This article is an open access article distributed under the terms and conditions of the Creative Commons Attribution (CC BY) license (http:/ / creativecommons.org/licenses/by/4.0/). 